\title{
A Perspective of Lignin Processing and Utilization Technologies for Composites and Plastics with Emphasis on Technical and Market Trends
}

\author{
Marcel Kropat, Mochen Liao, Hyeonji Park, Khandoker S. Salem, Shelly Johnson, and \\ Dimitris S. Argyropoulos*
}

\begin{abstract}
This effort is focused on work completed publicly and privately within academic research and industrial sectors on the utilization of lignin to produce thermosets, thermoplastics, foams, hydrogels, and rubbers. The size of the plastics market and the current and projected influence of lignin on it were evaluated. Further, an analysis of patent activity was employed to show the direction of and interest for lignin in these markets. The market trends documented in the literature, when coupled with detailed patent research, offer a new approach to evaluate potential markets and future directions. The analysis of the commercial market sizes of bioplastics and segmentation showed low penetration of actual lignin-based bioplastics. This exposed the contradiction between the abundance of technologies for lignin-based materials and their little practical use. In addition, this finding highlighted a severe gap between lignin research and development and the actual market.
\end{abstract}

Keywords: Biopolymers; Bioplastics; Lignin; Market trends; Patents; Renewable resources

Contact information: Department of Forest Biomaterials, North Carolina State University, 2820 Faucette Drive, Raleigh, North Carolina, 27606, USA; *Corresponding author: dsargyro@ncsu.edu

\section{INTRODUCTION}

Global environmental awareness and sustainability efforts have gained momentum, which has increased the need for environmentally friendly primary resources for chemicals, materials, and energy. Thus, the concept of biorefinery has stemmed from the research and development of biomass products to tackle such key societal and technological challenges (Passoni et al. 2016). International Energy Agency Task 42 coined a formal definition for biorefinery as "the sustainable processing of biomass into a spectrum of bio-based products (food, feed, chemicals, and/or materials) and bioenergy (biofuels, power, and/or heat)" (Jungmeier et al. 2015). Biorefinery can be a concept, a facility, a process, a plant, or even a cluster of facilities that provide a sustainable approach to valuable products. It can improve biomass processing economics and environmental impact (e.g., greenhouse gas savings) if a fully integrated concept is developed.

Among the various products of biorefinery, lignin is an indispensable and valuable component. Both renewable energy and renewable chemical practices must be adopted for a sustainable economy based on biorefineries. However, due to the current low price of oil, biorefineries require improved profitability to compete with fossil fuels. This can be accomplished by manufacturing diversified products and effectively utilizing byproducts for materials applications (Ho et al. 2018). Petroleum-based chemicals have been the primary feedstock for the production of commodity plastics since the 1940s. Due to limited 
petroleum resources, the focus has shifted towards the identification of renewable feedstocks as substitutes for the currently used non-renewable petroleum-based materials. In an effort to increase sustainability, the U.S. Department of Energy and the U.S. Department of Agriculture are strongly committed to expanding the role of biomass for the energy and chemical industry. An increase in the proportion of commodity chemicals and materials made from renewable feedstocks from 5\% in 2005 to $25 \%$ in 2030 is predicted (Perlack et al. 2005). Lignocellulosic biomass can be utilized for a variety of different materials, such as chemicals and biofuels, and it is the most accessible renewable carbonbased feedstock (Upton and Kasko 2016).

The three main components of lignocellulosic biomass are cellulose, hemicellulose, and lignin, whereby the mass percent composition is dependent on the plant species. Cellulose, a polymer of glucose, incorporates $30 \%$ to $50 \%$ of the biomass. Hemicellulose, a heteropolymer of various monosaccharides, represents a smaller portion of $20 \%$ to $35 \%$. The remaining $15 \%$ to $30 \%$ of the lignocellulosic biomass consists of lignin. Lignin is a cross-linked heteropolymer that promotes structural integrity in the bio-composite. The aromatic-based amorphous polymer consists of various phenyl propane units linked by carbon-carbon and ether bonds. As the second most abundant natural polymer, lignin accounts for approximately $30 \%$ of organic carbon in the biosphere. According to Tuck et al. (2012), as lignin is the only scalable renewable feedstock composed of aromatic units, it is highly underutilized. In 2010, only $2 \%$ of the 50 million tons of lignin produced in pulp- and papermaking processes was utilized for specialty products. The largest proportion (48\%) was used as low-value fuel (Upton and Kasko 2016). This underutilization indicates a need to develop processes to efficiently isolate lignin from biomass and engineer lignin-based products with increased commercial value.

However, the purity and consistency of the products obtained from petroleumbased starting materials are redeeming qualities. Though lignin is a bio-based product that contributes to more renewable and sustainable products, its heterogeneity is a major technical drawback. Furthermore, the established infrastructure and favorable economics of petrochemical feedstocks inhibit the ability of lignin to be considered as a viable substitute. In this analysis, the patent search and subsequent market analyses were solely based on lignin and current commodity polymers. Overall, this work did not examine the uses of lignin as direct replacement molecules (of monomeric or oligomeric nature as would be derived by catalytic lignin degradation approaches). Further, this approach, if technically and economically resolved, could be a substantial contributing factor to the emergence of "lignin-to-polymer" products.

To comprehensively explore these issues, this review examined the various stages of development in using lignin in different polymer markets, which included the full range from laboratory-scale to industrial, commercial, and market considerations.

\section{LIGNIN PRODUCTION AND MODIFICATION}

\section{Current Production of Lignin}

The heterogeneity of lignin offers extreme difficulties for technical processes that require a uniform lignin product (Argyropoulos 2014). For example, polymerization processes often require precise stoichiometry that cannot be met by "unrefined" technical lignins. This can be attributed to the fact that the pulping processes are aimed at creating paper or other products, not lignin. The use of a variety of feedstocks, process conditions, 
manufacturing processes, and pulping sequences, etc., tends to deliver heterogeneous lignin products (Cui et al. 2014). This is further compounded by the fact that the delignification statistics cause the inherent production of lignin fragments, whose molecular weights and distributions $\left(M_{\mathrm{w}} / M_{\mathrm{n}}\right)$ are governed by the Flory-Stockmayer equations that contain critical exponents. Such exponential processes are very hard to precisely control (Argyropoulos and Bolker 1987a,b,c). This situation results in tremendous structural, polymeric, and functional group variations that need to be addressed prior to any successful implementation of value-added processes with lignin. In this respect, one may cite a variety of efforts of lignin utilization within the confines of the enumerated variations (Pan et al. 2013; Du et al. 2014; Duval and Lawoko 2014; Laurichesse and Avérous 2014; Thakur et al. 2014; Mendis et al. 2015; Kun and Pukánszky 2017; Tribot et al. 2019). However, recently, a welcome review has appeared in the literature that precisely addresses the various fractionation processes available (Gigli and Crestini 2020).

Because lignin is a major bio-based aromatic material, its importance and relevance to the petrochemical-based industrial economy are immense. Most valorized lignins include materials produced from the following processes: lignosulfonate, kraft, organosolv, and soda. Other methods include steam explosion and processes using various catalysts, which are called catalytic processes. The first step in isolating lignin from the native biomass is delignification, which involves the separation of the lignin from the cellulose, hemicellulose, and extractives. After delignification, the modification or lignin fractionation stage follows. Each pathway in a process influences the quality and purity of the lignin product. The following sections of the review summarize the delignification and the ensuing modification stages.

\section{Delignification}

The delignification stage is used to separate lignin from the other biomass components, which are mainly cellulose and hemicellulose. The pulp and paper and bioethanol industries are large-scale operations that use commercially proven techniques. The delignification methods differ based on the active species and process conditions used. The soda and kraft processes each treat the biomass at high temperatures (ranging from $155^{\circ} \mathrm{C}$ to $175^{\circ} \mathrm{C}$ ) for up to $5 \mathrm{~h}$ under basic conditions $\left(\mathrm{OH}^{-}\right)$for the soda process and a combination of $\mathrm{OH}^{-}$and $\mathrm{SH}^{-}$nucleophiles for the kraft process. The sulfite process operates under reaction times and temperatures similar to the soda and kraft processes but under acidic conditions using acid bisulfite or bisulfite as the reactants. Steam explosion is a process that treats the biomass with steam before explosively decompressing the biomass/steam mixture. Finally, the organosolv process uses polar solvents, such as ethanol, methanol, formic acid, and/or acetic acid, at elevated temperatures. Common to all methods is the final lignin precipitation stage. Each of these processes results in an extracted lignin product with a large variety of average molecular weights, polydispersity indices (PDI $=M_{\mathrm{w}} / M_{\mathrm{n}}$ ), and functional groups depending on the nature and the intensity of the delignification process applied, which exemplifies various heterogeneity concerns (Argyropoulos 2014; Cui et al. 2014).

\section{Chemical Modification of Lignin}

Various lignin modification stages have been proposed and mainly developed to address its compatibility with synthetic polymers via improving the mechanical and thermal stability characteristics (Figueiredo et al. 2018). Such lignins have seen utilization 
as fuels (Wang et al. 2015; Cheng and Brewer 2017), fuel additives (Chuck et al. 2013; Ogunkoya et al. 2015), chemicals (Schutyser et al. 2018), and polymers (Pan et al. 2013; Su et al. 2013; Mendis et al. 2015).

The functional groups of lignin (hydroxyl, methoxyl, carbonyl, carboxyl groups, etc.) are usually targeted to create various lignin derivatives. The precise modification is generally decided depending on the intended application, the reactivity of the functional groups, and the type of lignin used in the reaction. The chemical modification of lignin usually offers enhanced solubility for the modified lignin in organic solvents, makes the lignin production process more straightforward, and decreases the brittleness of the polymer with lignin. Therefore, lignin has emerged as a possible precursor to a variety of polymer applications, including higher value end uses. Chemistries that can be applied to lignin are, among others, methylolation (hydroxymethylation), demethylation, amination, and phenolation (Gonçalves and Benar 2001; Zhang et al. 2013). Sulfomethylation is the means by which methyl sulfonate groups are attached to lignin using a variety of $\mathrm{pH}$ and temperature levels and/or reactants (Konduri and Fatehi 2015; Chen et al. 2019). Depending on the conditions, the solubility of the sulfomethylated lignins in water is controlled. For example, such lignins have been applied to cement admixtures as a dispersant by Huang et al. (2018). A mixture of formaldehyde and sodium sulfite was used to generate sodium hydroxymethylsulfonate, the reactive reagent for the sulfomethylation.

Amination uses the Mannich reaction, which is a relatively simple and straightforward reaction among the possible lignin modification reactions. The amination of lignin can be achieved under acidic, neutral, or alkaline conditions (Matsushita and Yasuda 2003; Du et al. 2014; Wang et al. 2016; Wang et al. 2018; Jiao et al. 2019). Depending on the actual conditions, the reaction can either occur between the deprotonated phenolic lignin and the used N,N-dialkylated amine alcohol or between the phenolic lignin and the iminium ion. Aminated lignins are developed for use as emulsifiers or surfactants (Figueiredo et al. 2018).

There is a relative abundance of phenolic and aliphatic hydroxyl groups within the various technical lignins. Substitution reactions using these groups is another major method used to modify technical lignins to obtain lignin polyol derivatives. Esterification is a facile and simple reaction that allows the formation of lignin macromolecular forms of ligninbased polyesters (Duval and Lawoko 2014). Esterification can be carried out by ringopening reactions, condensation, or dehydration polymerization chemistries. In addition, epichlorohydrin or alkylene oxides have been co-polymerized with lignin. Lignin alkylation (Liu and Li 2006) is another type of modification that uses reactants, such as diazoalkanes and alkylsulfates, in the presence of sodium hydroxide. The phenolation of lignin is among the most widely examined reactions used to replace phenol with technical lignin (Tan 1996; Effendi et al. 2008). Phenolation is used to increase the reactivity of lignin for a variety of applications. Lignin is reacted with phenol under acidic conditions, resulting in the condensation of phenol with lignin side chains. The increase in phenolic hydroxyl groups as well as the readily available reactive sites lead to an improvement of the reactivity of the molecules (Jiang et al. 2018). Lignosulfonates and kraft lignin are commonly investigated lignin starting materials to which phenolation is applied. Efforts to remove methyl groups from the methoxyl substituents in the aromatic rings of lignin to create demethylated lignins have also appeared in the literature (Duval and Lawoko 2014; Laurichesse and Avérous 2014). 


\section{Lignin Applications}

Lignin-derived thermoplastics

Thermoplastics are polymers that can be liquefied via melting and then reversibly cooled for multiple cycles without notable effects on their inherent properties. Thermoplastic material is composed of polymer chains that are associated via noncovalent intermolecular forces. Thus, these materials offer low melt viscosities, excellent processing ability, good thermal stability (at processing temperatures and sometimes at operating temperatures), and robust mechanical properties (Mendis et al. 2015; Upton and Kasko 2016).

Lignin-based thermoplastic materials have shown improved processing abilities and recyclability compared to lignin-based thermosetting polymer networks (Wang et al. 2016). As such, they have gained increased interest as sustainable, cost-effective, and biodegradable alternatives for petroleum-based thermoplastics. However, lignin has a high glass-transition temperature $\left(T_{\mathrm{g}}\right)$ and undergoes radical-induced self-condensation at high temperatures (Pouteau et al. 2004; Sadeghifar et al. 2012; Sadeghifar and Argyropoulos 2015), which limits its thermal processing ability and eventually hinders the development of high-performance thermoplastic materials. To address these issues, plasticizers or compatible polymers with low $T_{\mathrm{g}}$ values have been added to lignin via blending or chemical modification.

Presently, lignin or its derivatives are blended or mixed with different thermoplastic polymers to prepare lignin-based thermoplastic materials. The most commonly used thermoplastic polymers are polyethylene (PE), polypropylene (PP), polyvinyl chloride (PVC), polyacrylonitrile (PAN), polymethylmethacrylate (PMMA), polyvinyl alcohol (PVA), ethylene-vinyl acetate copolymer (EVA), polyester, starch, and protein (de Chirico et al. 2003; Pouteau et al. 2003, 2004; Liu and Li 2006; Mu et al. 2009; Hu et al. 2011; Mansouri et al. 2011; Barzegari et al. 2012; Huo et al. 2012; da Silva et al. 2013; Thakur et al. 2014; Domínguez-Robles et al. 2018). Most thermoplastics are prepared using meltmixing and solution-mixing techniques at temperatures of approximately $170{ }^{\circ} \mathrm{C}$ to $210{ }^{\circ} \mathrm{C}$. To produce thermoplastics with melt-mixing, the standard methods used are extrusion, compression, injection, and blow-molding. In contrast, melt-mixing uses casting molding techniques. However, lignin/polyolefin thermoplastic composites are brittle materials with relatively high $T_{\mathrm{g}}$ values with the polar groups in lignin, which limit their compatibility within the nonpolar polyolefin matrix. Plasticizers used in melt-mixing are usually applied during blending with the goal of increasing the interactions on the interfaces of the blended polymers, decreasing micro-phase separation within the composite, and improving the performance of such composite materials (Su et al. 2013). Bouajila et al. (2006) reported that hydrogen bond forming molecules are suitable plasticizers for dry lignin and that aromatic molecules with a structure similar to monolignols (e.g., vanillin) are more appropriate for hydrated lignin (Gandini et al. 2002). In addition, the mechanical properties of lignin-based thermoplastics can be improved using polymer blending techniques (Wang et al. 2016). Few polymers are miscible with lignin through hydrogen bonding and acid-base interactions. Miscibility effects depend on the lignin content, as phase separation occurs at high lignin contents (Nahmany and Melman 2004; Effendi et al. 2008). Lignin/polyester composite systems, in contrast to other materials, display improved compatibility and overall performance due to the formation of hydrogen bonds between the carbonyl groups of the polyester matrix and the hydroxyl groups of the lignin (Canetti and Bertini 2007, 2009). Lignin can also be incorporated into thermoplastics and composites as a filler. The presence of its aromatic 
moieties improves the antioxidant, flame retardant, and (some) mechanical properties of the ensuing materials; further, water resistance and thermal stabililty are improved (de Chirico et al. 2003; Pouteau et al. 2003; Košíková et al. 2007; Ago et al. 2012; Barzegari et al. 2012). However, some of the observed improvements (i.e., enhanced thermal stability) depend on the improved miscibility of lignin with various polymers. The compatibility of lignin-thermoplastic blends could be easily improved by selecting a suitable structure of the polymer matrix in conjunction with the mixing technique. Further, the compatibility of lignin-based thermoplastics depends on the hydrogen-bonding interactions between the hydroxyls of lignin and thermoplastic polymers. It varies with the abundance of the different aromatic and aliphatic hydroxyl groups in lignin. Better compatibility can be obtained through modification of the macromolecules to create new active chemical sites via methods such as alkylation (Liu and Li 2006), hydroxyalkylation (Mu et al. 2009; Hu et al. 2011; Mansouri et al. 2011; da Silva et al. 2013), amination (Huo et al. 2012), and nitration (Huang and Zhang 2002). Furthermore, the compatibility can be improved by selective masking of the reactive hydroxyl groups in lignin by different chemical modification methods, such as esterification (Gandini et al. 2002; Nahmany and Melman 2004), phenolation (Tan 1996; Effendi et al. 2008), etherification (da Silva et al. 2009; Ahvazi et al. 2011; Sadeghifar et al. 2012), urethane formation (da Silva et al. 2009; Hatakeyama et al. 2013), polymer grafting (Kim and Kadla 2010; Wang et al. 2011), and copolymerization (Gao et al. 2012; Cinelli et al. 2013; Laurichesse and Avérous 2014). Recently, specific molecular weight fractions of kraft lignin have been shown to offer beneficial melt, thermal stability (Sadeghifar and Argyropoulos 2016), and antioxidant characteristics (Sadeghifar and Argyropoulos 2015) for blends with polyethylene, which has opened novel utilization possibilities.

\section{Lignin-derived thermosets}

Thermosets are three-dimensionally cross-linked polymeric materials formed via a polyfunctional polymerization (curing) process of reactive resins. Usually, before curing, the components are of lower viscosity than thermoplastics, which makes such systems ideal for the creation of fiber-reinforced composites. Due to its highly branched structure and its large number of functional groups, lignin appears to be a suitable bio-based component for resin formulations of thermosets and thermoset composite materials. In particular, for phenol-formaldehyde (PF), polyurethane (PU), and epoxy (EP) resin systems, lignin may act as a reinforcement and/or a possible replacement of petroleum-based resources. The preparation of lignin-based thermosets follows two general approaches. In one method, lignin is chemically modified to enhance its reactivity. Such lignin materials can be utilized to partially substitute conventional resin components or act as a reactive components, such as toughening or curing agents, in resin systems. Among other methods, chemical modification is typically accomplished by esterification (de Oliveira and Glasser 1994; Hirose et al. 2002; Matsushita et al. 2011; Chung et al. 2013), phenolation (Nimz 1969; Gierer and Pettersson 1977; Kratzl and Oburger 1980; Tan 1996; Lin et al. 2001; Effendi et al. 2008), and oxypropylation (Nadji et al. 2005; Cateto et al. 2009; Sadeghifar et al. 2012). In another approach, petroleum-derived components are partially substituted with crude lignin. However, due to the polarity of the lignin units and the resulting selfinteractions, the degree of substitution is limited. High substitution rates with crude lignin result in the compounded bioplastic exhibiting poor mechanical properties (Laurichesse and Avérous 2014; Kun and Pukánszky 2017). Both approaches are partial solutions, as the conventional petroleum-based components are not entirely substituted. Detailed 
reviews have been conducted on the topic of lignin-derived thermosets and are highly recommended for further reading (Feldman 2002; Lora and Glasser 2002; Matsushita and Yasuda 2003; Raquez et al. 2010; Sen et al. 2015; Ma et al. 2016; Wang et al. 2016; Kun and Pukánszky 2017).

\section{Phenolic resins}

Phenolic resins (PF-resins) are well known for their dynamic stability and water resistant, chemical resistant, and electrical insulating characteristics. Typical applications for PF-resins are coatings, adhesives, and molded products. These resins are produced either in acidic or basic media (Olivares et al. 1988; Gardziella et al. 2000; Sen et al. 2015). The synthesis of PF-resins occurs via the reaction of formaldehyde with the ortho- and para- positions of phenol. The result is a three-dimensional, cross-linked network (Duval and Lawoko 2014). For a reaction with formaldehyde to occur, at least one of the orthogroups of the lignin-monomers must be unsubstituted (Sen et al. 2015).

Due to the similar chemical structures of polyphenolic lignin and phenol, the use of lignin to prepare phenolic resins has been extensively examined, and the topic has been subjected to numerous literature reviews (Wang et al. 1992; Belgacem and Gandini 2008; Lora 2008; Doherty et al. 2011; Duval and Lawoko 2014). The need for low-cost adhesives of reliable supply and durability is a driving factor for the substitution of phenolic components with different lignin types. Primary application targets for these lignin-based phenolic resins are composites, adhesives, insulation, lamination, wood bonding, molded parts, and plywood-adhesives (Barrett 2018). The degree of substitution in phenolic resin systems by crude lignin is limited, as the deterioration of the properties is proportional to the amount of lignin substituted. As a result, recent research has mainly focused on purified, functionalized, and fractionated lignins with higher reactivity for application in phenolic resin systems (Kun and Pukánszky 2017). Even with modified lignin, the substitution rate of classic phenols in the industrial-scale production of lignin-based PFresins is limited. However, UPM recently announced a $100 \%$ lignin-based phenolic resin (Wisa BioBond) that is produced on a commercial scale (Barrett 2018).

\section{Epoxy resins}

Epoxy resins account for $70 \%$ of the global production of thermosets (Ma et al. 2016). Approximately $90 \%$ of epoxy precursors use bisphenol A and epichlorohydrin. However, bisphenol A is an environmentally hazardous molecule, as it can cause cancer, infertility, and impotence, and it has been reported to be hazardous to young children and infants (Asada et al. 2015). The use of bisphenol A in materials that come into contact with food has been banned in several countries, and the use of non-toxic, renewable alternative resources is under serious consideration (US FDA 2010; Flint et al. 2012). The production of epoxy precursors based on renewable resources, such as lignin, has been reported and accordingly reviewed (Duval and Lawoko 2014; Thakur et al. 2014; Sen et al. 2015; Ma et al. 2016; Sun et al. 2018). Modified lignins can be used as both the epoxy component and the curing agent for the synthesis of epoxy resins. However, due to its high molecular weight, crude lignin is not suitable as an epoxy component alone. The resulting epoxy resins from crude lignin are usually characterized by low curing reactivity and unstable properties due to the complex structure and the low mobility of the macromolecules.

Further, the compatibility of crude lignin with curing agents is rather low (Hofmann and Glasser 1993, 1994). However, lignin derivatives of a relatively low molecular weight and enhanced reactivity are currently a prominent feedstock for epoxy resins (Ma et al. 
2016). The epoxidation of lignin is performed by reacting its hydroxyl groups with epichlorohydrin, which is followed by epoxide ring closure in alkaline media. The created lignin epoxides are then mixed with curing agents, which causes cross-linking of the resin components. Curing agents contain reactive hydrogen atoms in the form of an amine, anhydride, carboxyl, or hydroxyl groups. Notably, unmodified lignins can also be adequate curing agents without chemical modification, as they contain carboxyl and hydroxyl groups (Kun and Pukánszky 2017).

\section{Polyurethanes and foams}

Polyurethanes (PU) are synthesized via the reaction of di- or poly-isocyanates and polyols that possess terminal hydroxyl groups (Engels et al. 2013). As lignin contains many phenolic and aliphatic hydroxyl functionalities, it can be used to replace the polyol component of polyurethanes (Zhang et al. 2015). Lignin-based PUs are more biodegradable than petroleum-based PUs (Cateto et al. 2014; Hu et al. 2014). Both the aliphatic and phenolic hydroxyl groups of lignin react with an aliphatic isocyanate to form polyurethanes with low $T_{\mathrm{g}}$ (Gandini et al. 2002; Bonini et al. 2005). However, high molecular weight polyurethane can be produced by controlling the feedstock (kraft, alcoholysis, lignosulfonate, or solvolysis lignin), polyols (PEG or PPG), polymeric methyldiisocyante, reaction time, and temperature (Thring et al. 1997; Hu 2002; Duong et al. 2014). However, lignin content was found to be the dominant determinant of material properties over other factors, such as the molecular weight of the polyols, whereas the ratio of isocyanate to hydroxyl groups influenced the tensile properties to some extent and improved the thermal stability (Thring et al. 1997; Vanderlaan and Thring 1998; Pohjanlehto et al. 2014). Lignin-based rigid and flexible bio-foams have been prepared with better thermal conductivity than traditional fossil-feedstock-based polyurethanes due to their larger cell size and lower density.

Lignin is often functionalized to generate new active sites and to improve its chemical structure, which increases its solubility in organic solvents and improves its processing ability and reactivity. A particularly straightforward functionalization approach was reported by Chung and Washburn (2012). The authors demethylated the lignin with Lewis acid catalysts and generated $28 \%$ more hydroxyl groups, which produced polyurethanes with significantly improved cross-link densities (Chung and Washburn 2012). Esterification is another simple method that has been used to produce esterified lignin. These esterified lignins can generate lignin-oleic acid-based polyols that form polyurethanes with relatively low $T_{\mathrm{gS}}$ when reacted with polyisocyanates (Laurichesse $e t$ al. 2014). Further, the hydroxyl groups of lignin have been functionalized to develop rigid polyurethane foams with comparable insulating and physical properties to those derived from petroleum-based products (Nadji et al. 2005). The water solubility and durability of polyurethane products can be improved using the Mannich reaction, which introduces an amine group in the lignin structure using formaldehyde and a primary or secondary amine or ammonia (Liu et al. 2013). The development of lignin-based phosphate melamine polyurethanes has also been reported, as they showed improved compression strength, thermal stability, char residue formation, and self-extinguishment (i.e., flame retardancy) (Zhu et al. 2014).

Overall, lignin-based polyurethanes have tremendous potential as commodity materials because they display promising (and many times better) physical properties than their petroleum-based counterparts. However, the properties of lignin-based materials can vary due to the batch to batch variability of technical lignins. This is an important drawback 
that necessitates the development of processes that offer consistent lignin products. Lignin fractionation is such a process that may provide lignin fractions with tunable and coherent specifications and properties to the end users before entering the market (Argyropoulos 2014; Cui et al. 2014).

\section{Hydrogels}

Hydrogels are typically polymeric materials that can absorb water, which results in distinct swelling due to the onset of osmotic pressure within them (Passauer 2012). Acrylic acid has been used as a substantial component of commercial hydrogels. Many research efforts have been carried out on the use of biomaterials to create hydrogels. Lignin has been considered a potential source for hydrogel formation, which is mainly due to its documented biodegradability (Thakur et al. 2014; Collins et al. 2019; Meng et al. 2019). The topic of lignin-based hydrogels has been reviewed by several authors who investigated specific applications, such as water purification (Thakur et al. 2017), tissue engineering (Figueiredo et al. 2018; Witzler et al. 2018), biomedicine (Witzler et al. 2018), and biosensors or electrodes (Meng et al. 2019). Water purification aims to remove pollutants and ions from water, and lignin-based hydrogels are a promising resource in this area (Thakur et al. 2017). Lignosulfonate-based graphene hydrogels are composed of a highly porous structure and high specific surface area that has been reported to be able to capture $\mathrm{Pb}^{2+}$ with good endurance and reusability ( $82 \%$ adsorption efficiency after 10 cycles) (Li et al. 2016). Cellulose-lignin composite hydrogels and bentonite/sodium lignosulfonate/ acrylamide/maleic anhydride hydrogels were also used to adsorb $\mathrm{Pb}^{2+}$. Lignosulfonategrafted-acyclic acid-based hydrogels have also been examined for the adsorption of dyes in water (Thakur et al. 2017). Though excellent chelating performance was observed, the presence of bubbles within the hydrogel, due to entraining air during stirring, was problematic for its transparency. Lignin sulfonate-based mesoporous materials were found to address this problem with improved chelating efficiencies. Overall, Thakur et al. (2017) conclude that because lignins have shown promises in this area, technologies to produce quality lignin feedstocks are needed to promote interest in lignin-based hydrogels for the removal of pollutants from water (Thakur et al. 2017).

Another proposed use of lignin-based hydrogels was demonstrated by Figueiredo et al. (2018), who examined the use of lignin-based hydrogels for tissue engineering and found that operating temperature was a determinant of their functionality. Temperatureinduced gelation transitions (thermo-gelation) is a material behavior that occurs at temperatures lower than that of the human body and higher than room temperature. Atom transfer radical polymerization (ATRP) techniques, in which lignin is used as a core, have been developed to make a temperature-sensitive lignin-based hydrogel (Figueiredo et al. 2018). Furthermore, $\mathrm{Xu}$ et al. (2018) created lignin-based hydrogels using threedimensional printing techniques for various biomedical applications. The authors claimed that lignin has a high potential for use in applications such as cell adhesion using direct ink writing techniques (Xu et al. 2018). Notably, several lignin derivatives, including agaroselignin hydrogels with epichlorohydrin as the cross-linker, have been developed in steamcell-based tissue engineering (Witzler et al. 2018). Overall, Witzler et al. (2018) state that value-added lignin applications are currently of increased interest due to the fact that ligninbased hydrogels show considerable promise for the controlled or sustained release of pharmaceuticals (Witzler et al. 2018). 
Meng et al. (2019) classified the various areas of lignin-based hydrogels into four applications: absorption, controlled release, stimuli-responsive, and biosensors and electrodes. The preparation of lignin-based hydrogels towards biosensor application was conducted by copolymerization of organosolv lignin, lignosulphonates, and kraft lignin with poly(propylene oxide), blended with multiwall carbon nanotubes (Meng et al. 2019).

To enable the hydrogel to display conductivity, the lignin was modified with cations using ethyltrimethyl ammonium chloride. Graphene and lignosulfonate composites have also been introduced as metal-free supercapacitors (Li et al. 2017). Lignosulfonates have been reported to increase conductivity considerations in such hydrogels when compared to pure graphene hydrogels. Single-wall carbon nanotubes were also combined with lignosulfonates to display pressure-sensitive characteristics (Peng et al. 2018). The cited authors emphasize that lignin offers good possibilities for the creation of novel hydrogels, but the synthesis routes need to be improved in terms of simplicity, eco-friendliness, and efficiency.

\section{Rubbers}

Rubber is a vulcanized heterogeneous material, the property characteristics of which rely heavily on its reinforcement and binding components. Carbon black is the typical reinforcing agent used in rubbers, but lignin could potentially replace it. Such a replacement assumes that the added lignin will be of acceptable uniformity to offer economical and consistent reinforcement characteristics within stringent specifications (Kakroodi and Sain 2016).

The literature contains abundant accounts and reviews that demonstrate the beneficial effects of lignin on the mechanical and other properties of rubbers (Košíková et al. 2007; Bova et al. 2016; Datta et al. 2017) with possible commercial ramifications (Bova et al. 2016). For example, Košíková et al. (2007) conclude that the role of lignin in rubbers is both that of a strengthening and reinforcing agent and a thermal stabilizer (Košíková and Gregorová 2005; Košíková et al. 2007). Other efforts have also accounted for the resistance of lignin-containing vulcanized natural rubber against thermo-oxidative degradation effects (Barana et al. 2016). The work of Wang et al. (2018) with industrial alkali lignin reported that, when blended with carbon black, a lignin-rubber elastomer was produced with processing energy savings and notable benefits in the mechanical properties of the elastomer.

The miscibility of the lignin with various polymeric components within the rubber is of great importance in this area because such miscibility and compatibility considerations have a profound effect on the interaction between the various polymeric components, which is eventually reflected in the mechanical properties of the blend (Wang et al. 2018). Tran et al. (2016) attempted to enhance the miscibility of lignin in rubber composites and showed that improvements could be realized by using a fractionated melt-stable lignin (Tran et al. 2016). In addition, Yu et al. (2016) attempted to enhance the miscibility of lignin in rubber compounds with a fine dispersion of lignin by utilizing latex-compounding methods. Efforts to fundamentally understand and validate these considerations led Setua et al. (2000) to compare the properties imparted on rubber composites by crude and modified lignin preparations. They concluded that the modified lignin preparations offered better thermal stability and oil/fuel resistance than phenolic resins or carbon black additives (Setua et al. 2000). Other studies have also shown that methylated lignins offer good miscibility with natural rubber (Barana et al. 2018). 


\section{MARKET ANALYSES}

According to the Statistical Review of World Energy (BP Global 2018), the actual global oil reserves in 2017 consisted of 1,700 billion barrels, which would be sufficient to for $50.2 \mathrm{y}$ of global production at the 2017 level of consumption. However, the demand for oil in the global market is growing. For example, between 2016 to 2017, the growth rate was determined to be $1.8 \%$ per day, whereas a decade prior, the rate was $1.2 \%$ per day. China and the US were the largest contributors to this growth (BP Global 2018).

As resources based on fossil fuels are declining, global society has focused on alternative sources of energy and chemicals. Biomass is the most abundant renewable alternative to petroleum-based feedstock (L'udmila et al. 2015). Approximately 150 billion tons to 180 billion tons of biomass are produced annually. Approximately $75 \%$ of biomass is polysaccharides (cellulose and hemicellulose) and 20\% is lignin. The global annual increase of lignin is estimated at 20 billion tons per $\mathrm{y}$, and the total lignin availability in the biosphere is estimated at 300 billion tons (Blažej and Košík 1993; Gregorová et al. 2006; Rossilo-Calle et al. 2007; L’udmila et al. 2015; Bruijnincx et al. 2016).

\section{Lignin Markets}

Though approximately $95 \%$ of global lignin production is combusted to produce energy, only the remaining 5\% is marketed for substantial applications (Tribot et al. 2019).

A market report published by Grand View Research (2020) valued the global lignin market at approximately US\$954.5 million in 2019 . The report included a recent market analysis for the period of 2016 to 2018 and a forecast of the market for 2020 to 2027. The lignin market is expected to reach around US\$ 1.12 billion by 2027. The Compounded Annual Rate of Growth (CARG) (in terms of revenue) is projected to be $2 \%$ between 2020 and 2027. Macromolecules and aromatics are major applications in the lignin market. Macromolecules application accounted for approximately 58\% market share in 2019. Water-soluble sulfonates accounted for the largest market segment in macromolecules for 2019 and are estimated to maintain market dominance until 2027 (Grand View Research 2020). Approximately $85 \%$ of the existing lignin markets are dominated by water-soluble sulfonates, although sulfite pulping has virtually been replaced by kraft delignification in most countries. This preference of sulfite over kraft lignin is due to the nature of each process, whereby one process involves structural modification (via installation of sulfonate groups on lignin) and the other is based on structural degradation (via hydrolysis of alkyl aryl ether bonds). A CARG of $1.4 \%$ is anticipated for the demand for water-soluble sulfonates from 2020 to 2027. The market share of kraft lignin was over 7\% in 2019 (Grand View Research 2020).

The broad application range for products with lignin includes paints and coatings, building and construction, agrochemicals, and many others. Bioplastics made from lignin were not explicitly mentioned in the report (Grand View Research 2020). The growth of the global lignin market is attributable to the strong demand from these applications. The global lignin market is classified based on application segments. The application segments include concrete additives, dyestuffs, animal feed, and others. Over $45 \%$ of the global lignin market was used for concrete additives in 2019. According to the report, the North America region was dominant in the global lignin market, followed by Europe. However, Europe is expected to grow rapidly. Europe was followed by the Asia Pacific and Latin American regions, respectively. The fastest growing market during the forecast period is estimated to be the Asia Pacific market (Grand View Research 2020). 


\section{Bioplastics Market}

The bioplastics industry requires feedstocks based on renewable resources, such as polysaccharides and lignin from biomass. According to the European Bioplastics Report (European Bioplastics 2019), bioplastics represent less than 1\% of the current 335 million tons of plastic produced annually. The report predicted an increase in global production capacities from around 2.11 million tons to 2.62 million tons for 2023. Polylactic acid (PLA) and polyhydroxyalkanoates (PHA) were the main predicted drivers of this growth. Whereas the production capacities of PHAs were estimated to quadruple within the next 5 $\mathrm{y}$, the production capacities of PLA were predicted to grow $60 \%$ by 2023 . Bio-based polypropylene (PP) production on a commercial scale is expected to enter the market in 2023 (European Bioplastics 2019). Figure 1 shows the shares of the total global production capacities of 2.11 million tons in 2018 by material type (European Bioplastics 2019).
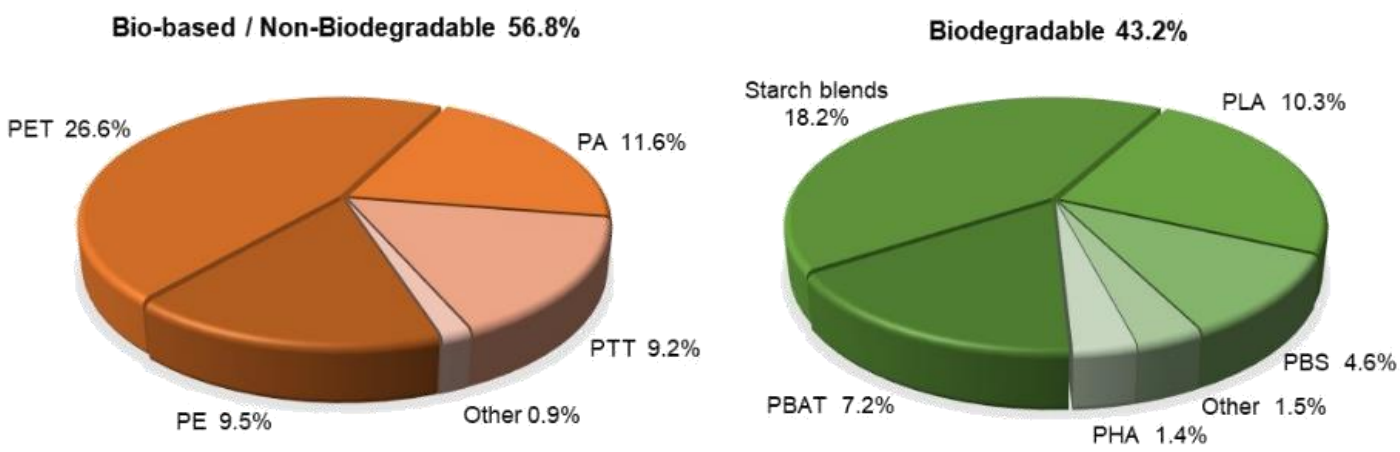

Fig. 1. Global production capacities of bioplastics in 2018 by material type; this figure was created with permission based on data from European Bioplastics (2019)

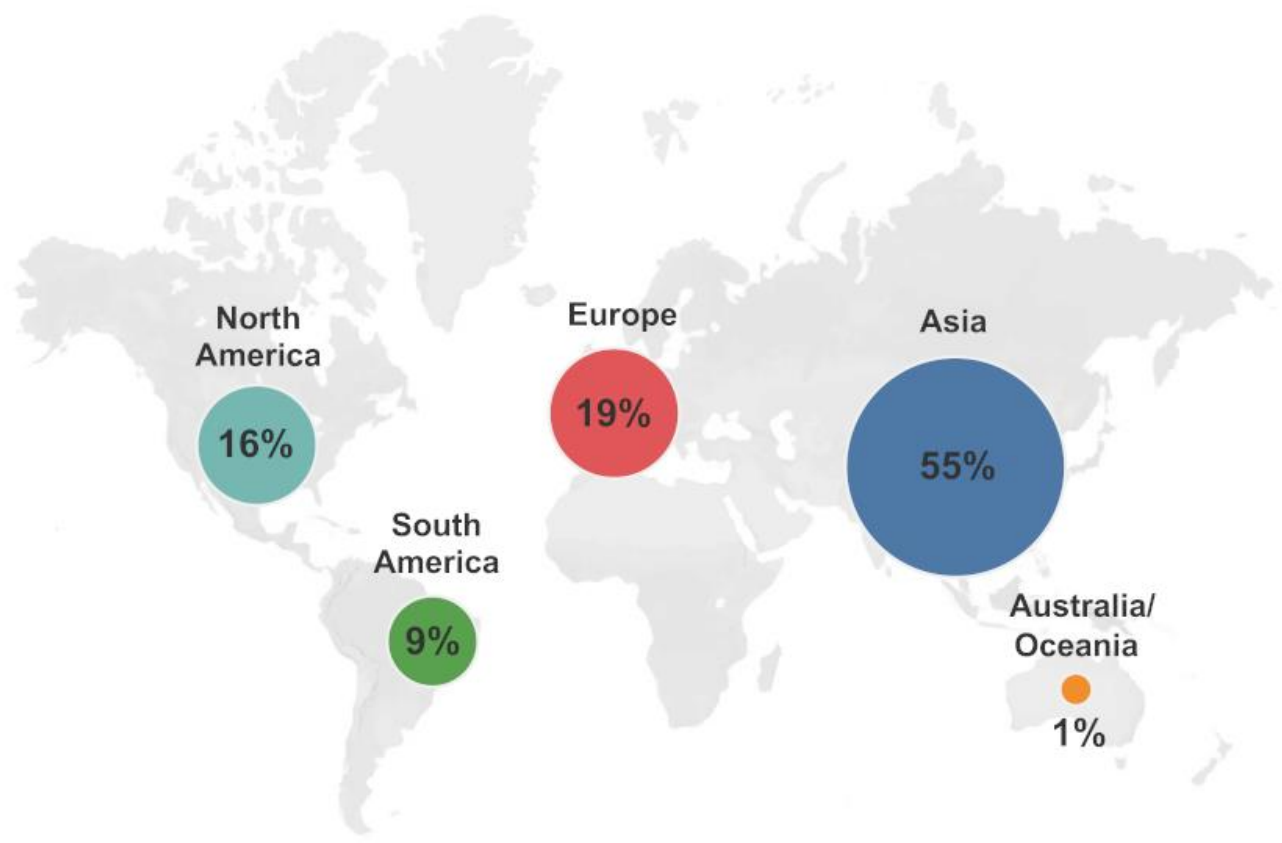

Fig. 2. The global production capacity of bioplastics in 2018 by region; this figure was created with permission based on data from European Bioplastics (2019) 
The report describes Asia (with 55\%) as the largest contributor to the production capacities of bioplastics, followed by Europe and the U.S., respectively. Figure 2 shows the distribution of the global production capacities of bioplastics by region.

The IBISWorld Industry Report (2018) for bioplastics manufacturing in the U.S reported data about the products and services segmentation of bioplastics in the U.S. The central segment for bioplastics $(34.1 \%)$ is starch-based bioplastics, whereas bioplastics from lignin were merged in the category of synthetic/others. Figure 3 shows the market shares of the different products and service segments in U.S. bioplastics production (IBISWorld 2018). The report illustrates the scarcity of lignin in current industry-scale applications because most bioplastics are made from polysaccharides. However, the market offers some lignin-based plastic composite materials (e.g., ARBOFORM ${ }^{\circledR}$ and ARBOBLEND®). These composites consist of natural fibers and a thermoplastic made from lignin (Naegele et al. 2016). Though Asia is the most substantial contributor to the bioplastics market in general, Europe is the largest contributor to the lignin-based production of bioplastics and composites, followed by the U.S. (Barrett 2018).

Segmentation of U.S. bioplastics market in 2018

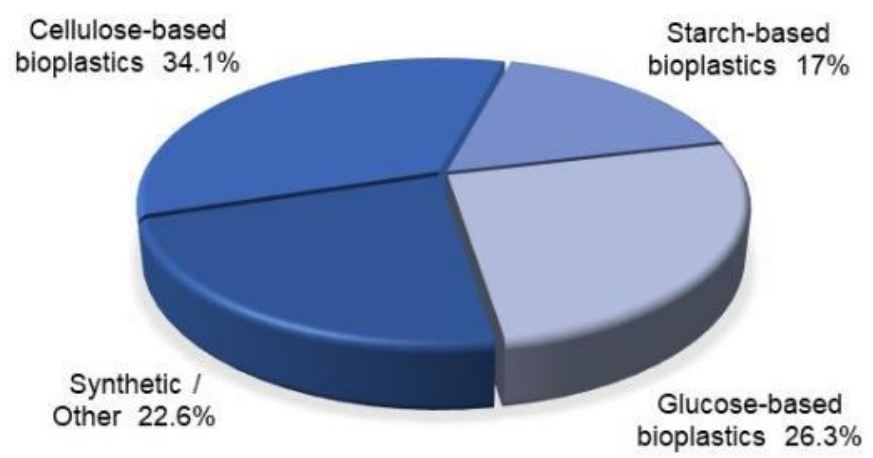

Fig. 3. The product and service segmentation of the U.S. bioplastics market in 2018; this figure was created with permission based on data from European Bioplastics (2019)

\section{TECHNICAL TREND ANALYSES}

Based on the analysis of the bioplastics commercial market sizes and segmentation examined above, the amount of actual lignin-based bioplastics that have penetrated the market is low. This exposes the contradiction between the abundance of technologies for lignin-based materials and their little practical use. Further, this reveals the existence of a serious gap between lignin research and development and the actual market. In the following sections, more informed data analysis is offered to reduce the gap between lignin research and the actual market by providing further insights to connect researchers, project managers, and stakeholders.

To address this gap, patent searches and a patent trend analysis methodology developed for this review were employed. Patents, which are globally the most popular means of intellectual property protection, may offer distinct advantages if used as a "technology indicator" (Mogee 1991). Because patents are the bridge that connects industrial applications to academic research, the analysis of patent data can be helpful for both academia and industry. Previous studies performed patent data analyses to determine technological trajectories in different domains, which included the low emission vehicle 
(LEV), radio frequency identification, and semiconductor industries (Almeida 1996; Oltra and Saint-Jean 2009; Trappey et al. 2011). Similar patent data analyses are applied in the ensuing text aimed to offer further insights.

\section{Methodology}

Patent search engine

Previous studies performed their patent data analyses based on the data provided by the European Patent Office (EPO), which offers a comprehensive collection of documents and the correlated search engine results in esp@cenet (ESPACENET) (Oltra and Saint-Jean 2009). The ESPACENET database contains patents applied for and granted all over the world (more than 70 countries and regions). It is a popular database for relevant technical analyses used in previous studies (Archibugi and Pianta 1992; Maurseth and Verspagen 2002). Though ESPACENET contains more than 110 million patent publications, another patent source with a broader range of patent data (European Patent Office 2019) was used, namely the Google Patent database. Google Patents, developed by Google Inc., includes the patents and patent applications from 17 different patent offices, including the United States Patent and Trademark Office (USPTO), China's National Intellectual Property Administration (CNIPA), Japan's Patent Office (JPO), Korean Intellectual Property Office (KIPO), World Intellectual Property Office (WIPO), Deutsches Patent- und Markenamt (PDMA), Canadian Intellectual Property Office (CIPO), EPO, and others (Google Patents 2019). To avoid replication, the patent data analysis was completed using both the ESPACENET and Google Patent databases/search engines separately. The detailed analysis method is shown in Fig. 4. The first step was a search to determine the number of patents related to specific search term(s), which was correlated to certain key-phrases.

\section{Data collection, refinement, and analysis}

As the present review article focused on the utilization of lignin-based materials, the key-phrases included "lignin" and specific material types. In Table 1, the key-phrases were divided into three groups, which corresponded to the feedstock of the production, the different applications of the produced materials, and the different categories of the produced polymer materials.

Table 1. Key-phrases Used for the Patent Data Analysis

\begin{tabular}{|c|c|c|}
\hline Group 1 & Group 2: Types of Polymer Materials & Group 3: Specific Polymer Materials \\
\hline Lignin & Thermoplastic & Polyethylene \\
\hline & Thermoset & Polyamide \\
\hline & Rubber & Polyethylene terephthalate \\
\hline & Foaming Material & Polypropylene \\
\hline & Hydrogel / Aerogel & Polyethylene furanoate \\
\hline & & Polylactic acid \\
\hline & & Polybutylene adipate terephthalate \\
\hline & & Polybutylene succinate \\
\hline & & Terephthalate \\
\hline
\end{tabular}

Based on these key-phrases, the patent data was then further refined via the following three stages, which had an increasing order of dependency:

- Stage 1: Patents whose content covered the key-phrase in Group 1 and the required key-phrase in Group 2 / Group 3 
- Stage 2: Patents in Stage 1 whose title covered the key-phrase in Group 1 or the required key-phrase in Group 2 / Group 3

- Stage 3: Patents in Stage 2 whose title covered the key-phrase in Group 1 and the required key-phrase in Group 2 / Group 3

Such refining of the patent data was instrumental in ensuring that the discovered patents had a strong correlation to the topics of lignin-based materials. Institutions may not always provide relevant titles to their patents for a variety of reasons. Such citations may partly invalidate some of the data derived from Stage 2 and Stage 3 of the patent search. However, such disparities, if they occurred, were anticipated to be of minor consequence. However, this limitation was included to ensure clarity. Further, some deficiencies may have existed in the presented method. For example, because the data in Stage 3 had a stronger dependence on the desired topic, it may have omitted some patents that use abbreviations of the key-phrases in Groups 2 and 3. Therefore, an additional analysis method was performed on the data extracted from Stage 2. The analysis method used the grant ratio (Eq. 1) and the spatial and temporal distributions of the refined patent data, the details of which are clarified in the ensuing discussion:

$$
\text { Grant ratio }=\frac{\text { Amount of granted patents searched by the key phrases }}{\text { Amount of total patents searched by the key phrases }} \times 100 \%
$$

Based on the process flow chart shown in Fig. 4, the patent data were initially collected from ESPACENET and the Google Patent search engines. The input parameters were the key-phrases in Groups 1, 2, and 3 (Table 1). Then, Stage 1 refinement was applied, and the data were downloaded and saved. For example, for a search of "lignin-based polyethylene," the input was "(lignin) AND (polyethylene)," which yielded all of the patents whose contents cover "lignin" and "polyethylene." Both Google Patent and ESPACENET provided downloadable CSV-files that allowed the detailed data for Stage 1 for a given topic to be collected. After obtaining the Stage 1 data, further analyses were conducted by proceeding to Stages 2 and 3 to arrive at spatial and temporal distributions and the grant ratios. All analyses were carried out by using the Python 3.6 programming language (Python Software Foundation, Version 3.6, Beaverton, OR, USA).
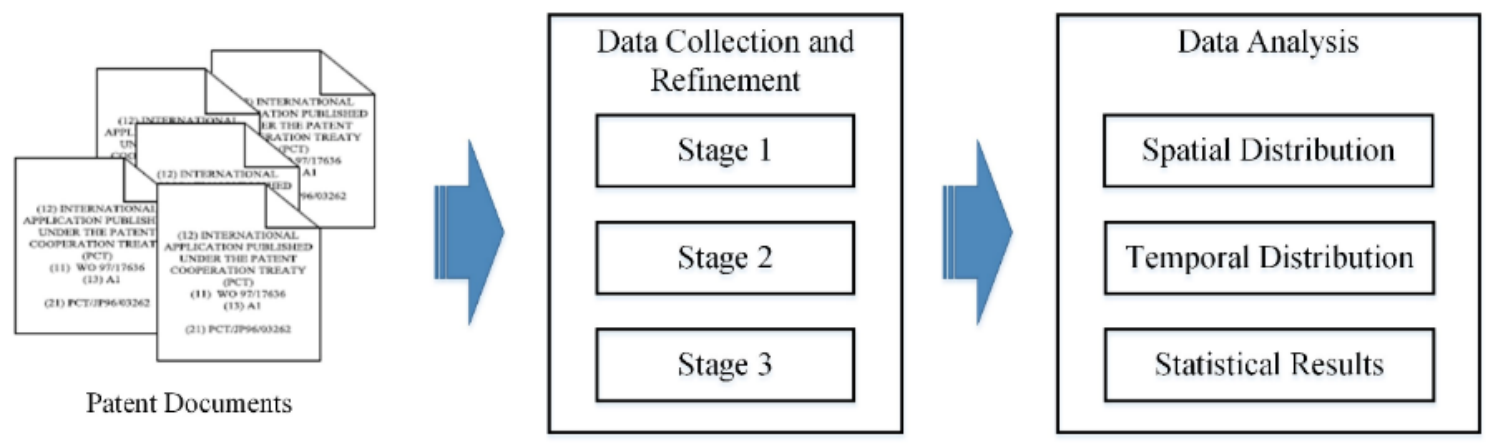

Fig. 4. Patent data analysis methodology

The spatial distributions categorized the patents by their countries of origin or the non-government organizations that published them (e.g., EPO and WIPO). The countries with the most patents are provided, discussed, and analyzed in the following text. The temporal distribution trends were examined for two different periods (a short one and a longer one). The short period showed the patent activity for the recent past $(20 \mathrm{y})$, 
highlighting recent technical trends. The longer period was used to display the patent activity from the beginning of the last century to offer a view of historical developments for a given research topic. Finally, the grant ratio provided insights into the possible commercialization of the relevant applications.

\section{RESULTS AND DISCUSSION}

\section{Data Refinement}

Table 2 provides the data refinement for Group 2 using the key-phrases shown in Table 1. The values in column Stage 1 directly reflect the relative size of the databases.

The size of the ESPACENET database is considerably smaller than the Google Patents database. Further, for some specific types of lignin-based materials, some notable differences were apparent. For example, in the Google Patents database, the number of patents for lignin-based foaming materials was 16571 (Stage 1). This was a much larger number than that for other types of lignin-based materials. However, in the ESPACENET database, the total number of lignin-based foaming materials patents was only 289 (Stage 1), which was lower than the number for lignin-based rubber (615 for Stage 1). Due to the relatively small size of the ESPACENET database, the grant ratio calculated from this database may not have been representative (e.g., lignin-based thermosets). Because of these discrepancies, further analyses used the results obtained from the Google Patents database.

Table 2. Group 2 Patent Data Refinement Results From Google Patent and ESPACENET

\begin{tabular}{|c|c|c|c|c|}
\hline & Stage 1 & Stage 2 & Stage 3 & $\begin{array}{c}\text { Grant Ratio in Stage } \\
2(\%)\end{array}$ \\
\hline \multicolumn{5}{|c|}{ Google Patents } \\
\hline Thermoplastics & 624 & 181 & 25 & 33.1 \\
\hline Thermosets & 4651 & 275 & 8 & 29.1 \\
\hline Rubber & 695 & 268 & 58 & 15.7 \\
\hline Foaming Materials & 16571 & 1285 & 45 & 16.2 \\
\hline Aerogel / Hydrogel & 1076 & 299 & 26 & 18.7 \\
\hline \multicolumn{5}{|c|}{ ESPACENET } \\
\hline Thermoplastics & 231 & 80 & 21 & 32.5 \\
\hline Thermosets & 18 & 9 & 2 & 77.8 \\
\hline Rubber & 615 & 234 & 56 & 10.3 \\
\hline Foaming Materials & 289 & 180 & 30 & 13.3 \\
\hline Aerogel / Hydrogel & 66 & 45 & 13 & 2.2 \\
\hline
\end{tabular}

To understand the degree of technical maturity of different types of lignin-based materials, the grant ratio was calculated. This is the number of patents granted in Stage 2 divided by the number of overall patents obtained in Stage $2(\times 100 \%)$ for a specific type of lignin-based material. Higher grant ratios indicate industry-preferred areas, in which technologies are likely more mature.

\section{Data analysis}

The grant ratios for different types of lignin-based materials based on the Stage 2 refined patent data are provided in Table 2 . The patents for lignin-based thermoplastics and 
lignin-based thermosets had higher grant ratios (33.2\% and $29.1 \%$, respectively) than other types of lignin-based materials. These two market segments are likely more mature than other types of lignin-based materials.

Tables 3 and 4 show the spatial distribution for lignin-based material patents. The top 5 countries with the highest patent activity in a given area are shown first, and the rest are combined and displayed as "Others." China, the United States, and Japan are at the top of the list and responsible for $64 \%$ to $83 \%$ of the total number of patents for all the different types of lignin-based materials examined.

Through comparing the number of patents (Stage 2 refinement) between China and the United States, it was evident that China had considerably higher activity in lignin-based foaming materials and lignin-based aerogels/hydrogels. In contrast, the United States had higher patent activity in the area of lignin-based thermoplastics, thermosets, and rubbers, which are more traditional materials than foaming material and aerogel/hydrogel applications.

Table 3. Group 2 Patent Data Spatial Distribution Results as Obtained From Google Patent

\begin{tabular}{|c|c|c|c|c|c|c|}
\hline & China & $\begin{array}{c}\text { United } \\
\text { States }\end{array}$ & Japan & WIPO & Korea & Others \\
\hline Thermoplastics & 35 & 91 & 13 & 13 & 5 & 24 \\
\hline Thermosets & 47 & 107 & 40 & 30 & 5 & 46 \\
\hline Rubber & 82 & 117 & 12 & 12 & 4 & 41 \\
\hline Foaming Materials & 653 & 272 & 118 & 73 & 36 & 133 \\
\hline Aerogel / Hydrogel & 168 & 66 & 5 & 34 & 16 & 10 \\
\hline Total & 985 & 653 & 188 & 162 & 66 & 254 \\
\hline
\end{tabular}

Table 4. Group 2 Patent Data Spatial Distribution Results From ESPACENET

\begin{tabular}{|c|c|c|c|c|c|c|}
\hline & China & $\begin{array}{c}\text { United } \\
\text { States }\end{array}$ & British & Japan & Canada & Others \\
\hline Thermoplastics & 29 & 17 & 5 & 5 & 2 & 22 \\
\hline Thermosets & 0 & 6 & 1 & 0 & 1 & 1 \\
\hline Rubber & 131 & 38 & 24 & 8 & 14 & 19 \\
\hline Foaming Materials & 122 & 16 & 8 & 11 & 3 & 20 \\
\hline Aerogel / Hydrogel & 34 & 1 & 0 & 0 & 0 & 10 \\
\hline Total & 316 & 78 & 38 & 24 & 20 & 72 \\
\hline
\end{tabular}

The developing trends for different lignin-based materials are also plotted as a function of two time domains to show recent and long-term trends. Figure 5 displays patent activities in the past $20 \mathrm{y}$ (Fig. 5a.) and the past $90 \mathrm{y}$ (Fig. 5b).

There has been notable recent activity in lignin-based foaming materials, aerogels, and hydrogels (Fig. 5a). These trends have accelerated in recent years, and lignin-based aerogels and hydrogels have been in a leading position since 2012. The patent activities for lignin-based thermoplastics, thermosets, and rubbers have stabilized during the past $20 \mathrm{y}$.

In summary, lignin-based foaming materials and lignin-based aerogels and hydrogels have been subject to increased recent patent activity, which likely indicates commercial interest and possible opportunities. 


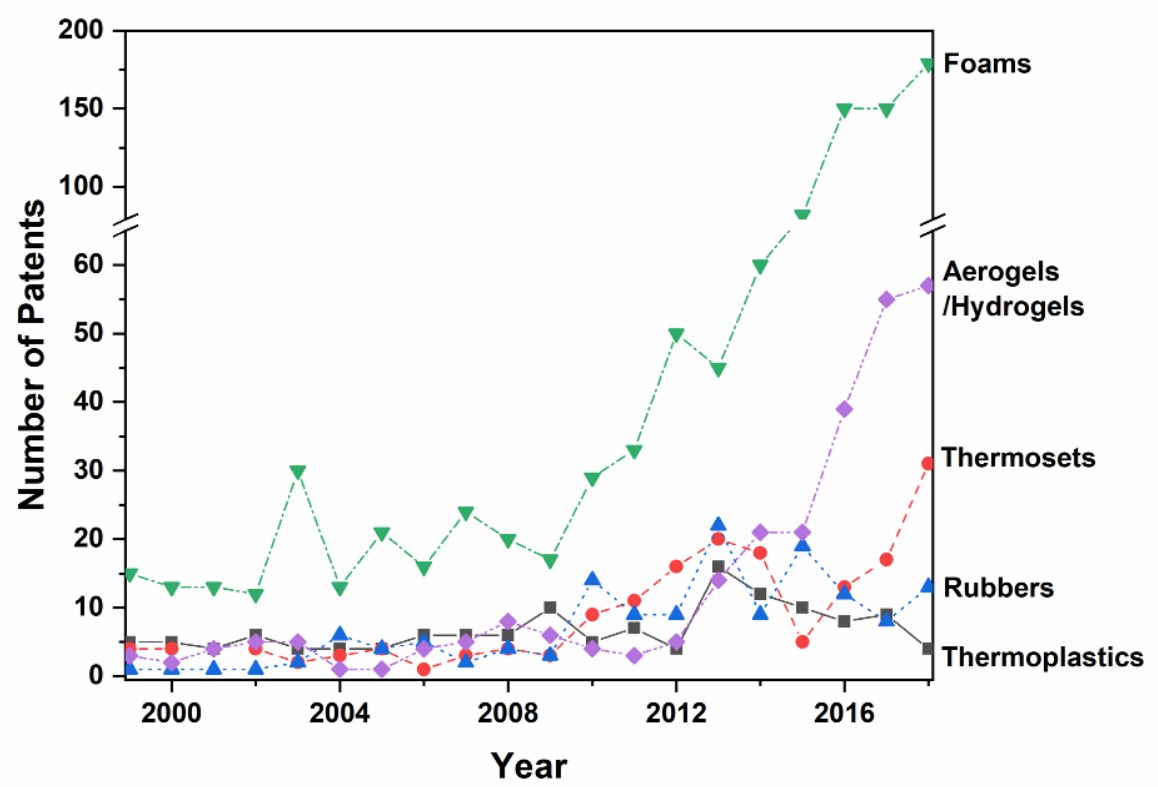

Fig. 5a. Group 2 Google Patent data distribution during the past 20 years

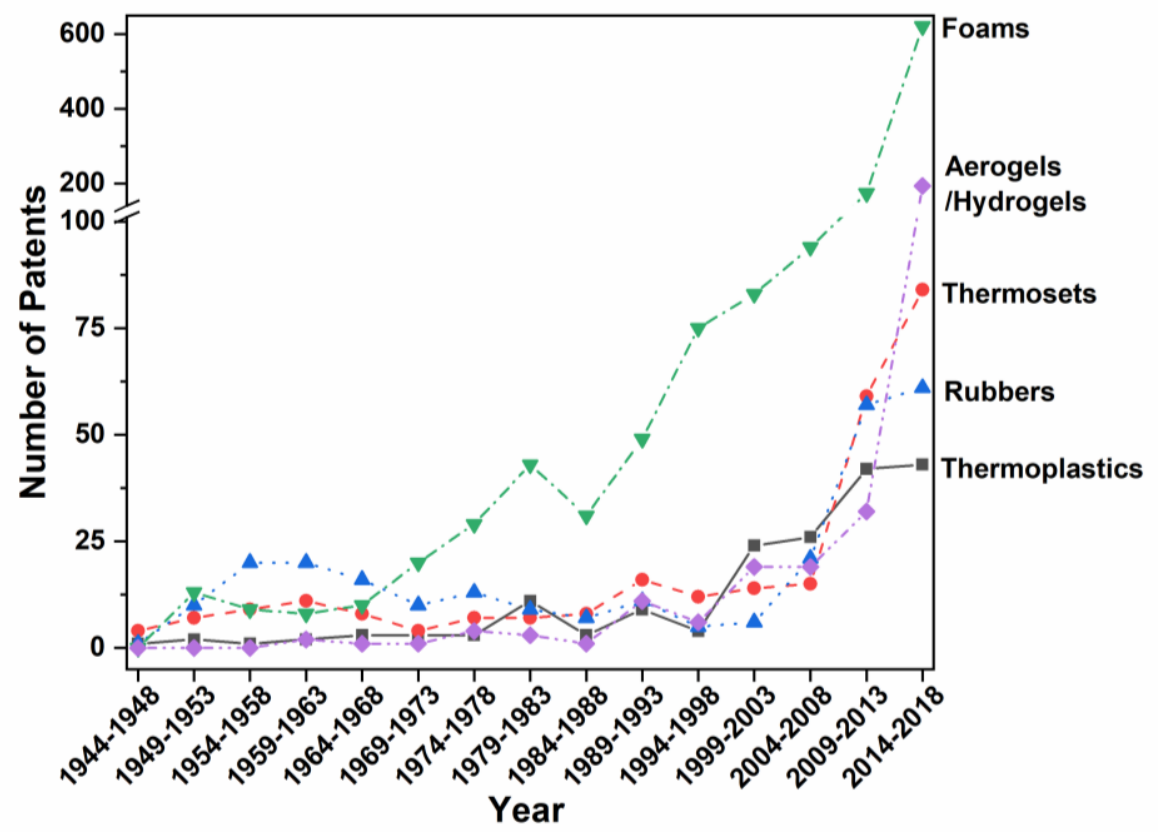

Fig. 5b. Group 2 Google Patent data distribution during the past 90 years

The long-term patent activity trends (Fig. 5b) for the different types of lignin-based materials showed a steadily increasing interest, which can be interpreted as an indicator of the prospective development of lignin-based materials. Interestingly, the number of patents for lignin-based rubber materials exceeded that of other types of materials from the 1950s to the $1970 \mathrm{~s}$, but the activity decreased in the $21^{\text {st }}$ century. Overall, the trends discovered and displayed in Fig. 5 can provide a valuable guideline for decision makers (industry, funding agencies, and academics) to determine the direction and importance of projects related to different types of lignin-based materials. 
An analysis of the patent activities for lignin-based blends and composites with various types of synthetic polymers follows. Similar approaches to those applied to Stage 2 were also used on the data accumulated in the patent data analysis of Group 3, which aimed at specific types of materials. In Table 5, the data refinement results based on key-phrases in Groups 1 and 3 are shown. The number of patents for lignin-based polyethylene (PE) (65781 in Stage 1) and polypropylene (PP) (53432 in Stage 1) far exceeded the number of patents for other types of polymers, which followed the same trend due to the high market penetration ratios of PP and PE (Witter 2015). The grant ratios of different lignin-based polymers are also listed in Table 2 .

However, some grant ratio data may have been unrepresentative due to small data sizes; thus, it was not included. For example, the number of patents in Stage 2 for polylactic acid, polybutylene adipate terephthalate, and polybutylene succinate was less than 50, whereas the largest number was higher than 1000 (1081 for polyethylene). Therefore, further analysis may be necessary to fully comprehend and validate the technological maturity of these lignin-based polymers. Table 6 shows the spatial distribution for the patent activity of lignin-based polymers. Like the results of Table 4, the top 5 countries with the highest patent activity are provided, and the number under "Others" is the sum of the patents from the remaining countries.

Table 5. Group 3 Patent Data Refinement Results From Google Patent

\begin{tabular}{|c|c|c|c|c|}
\hline & Stage 1 & Stage 2 & Stage 3 & $\begin{array}{c}\text { Grant Ratio in Stage } \\
2(\%)\end{array}$ \\
\hline Polyethylene & 65781 & 1081 & 19 & 18.22 \\
\hline Polyamide & 15245 & 253 & 5 & 24.90 \\
\hline Polyethylene terephthalate & 7216 & 90 & 6 & 23.33 \\
\hline Polypropylene & 53432 & 906 & 9 & 19.65 \\
\hline Polyethylene furanoate & 6199 & 141 & 0 & 30.50 \\
\hline Polylactic acid & 2676 & 45 & 0 & 11.11 \\
\hline $\begin{array}{c}\text { Polybutylene adipate } \\
\text { terephthalate }\end{array}$ & 997 & 18 & 0 & 0 \\
\hline Polybutylene succinate & 1332 & 21 & 0 & 14.29 \\
\hline Terephthalate & 8134 & 128 & 8 & 21.09 \\
\hline
\end{tabular}

Table 6. Group 3 Patent Data Spatial Distribution Results From Google Patent

\begin{tabular}{|c|c|c|c|c|c|c|}
\hline & China & $\begin{array}{c}\text { United } \\
\text { States }\end{array}$ & WIPO & Japan & EPO & Others \\
\hline Polyethylene & 476 & 238 & 75 & 66 & 33 & 193 \\
\hline Polyamide & 53 & 81 & 25 & 3 & 14 & 41 \\
\hline $\begin{array}{c}\text { Polyethylene } \\
\text { terephthalate }\end{array}$ & 25 & 34 & 8 & 7 & 2 & 14 \\
\hline Polypropylene & 306 & 271 & 54 & 57 & 45 & 173 \\
\hline Polyethylene furanoate & 19 & 63 & 15 & 7 & 4 & 33 \\
\hline Polylactic acid & 21 & 11 & 2 & 6 & 2 & 3 \\
\hline $\begin{array}{c}\text { Polybutylene adipate } \\
\text { terephthalate }\end{array}$ & 6 & 10 & 0 & 1 & 0 & 1 \\
\hline Polybutylene succinate & 9 & 4 & 1 & 4 & 0 & 3 \\
\hline Terephthalate & 43 & 40 & 9 & 8 & 7 & 21 \\
\hline Total & 958 & 752 & 189 & 159 & 107 & 482 \\
\hline
\end{tabular}


The sizable activities of China and the United States were apparent, as these countries had the most patent activity for all of the lignin-based polymers. They were followed by WIPO, Japan, and EPO. Interestingly, China showed higher activity in ligninbased polyethylene, polypropylene, polylactic acid, polybutylene succinate, and terephthalate, which have higher annual production (Witter 2015) and higher absolute numbers of patents than other types of lignin-based polymers. The United States was dominant in patent activity for the remaining types of lignin-based polymers, which may indicate differences in lignin-based polymer development between China and the United States.

Figure 6 displays the development trends for lignin-based polymers in short-term (Fig. 6a) and long-term (Fig. 6b).

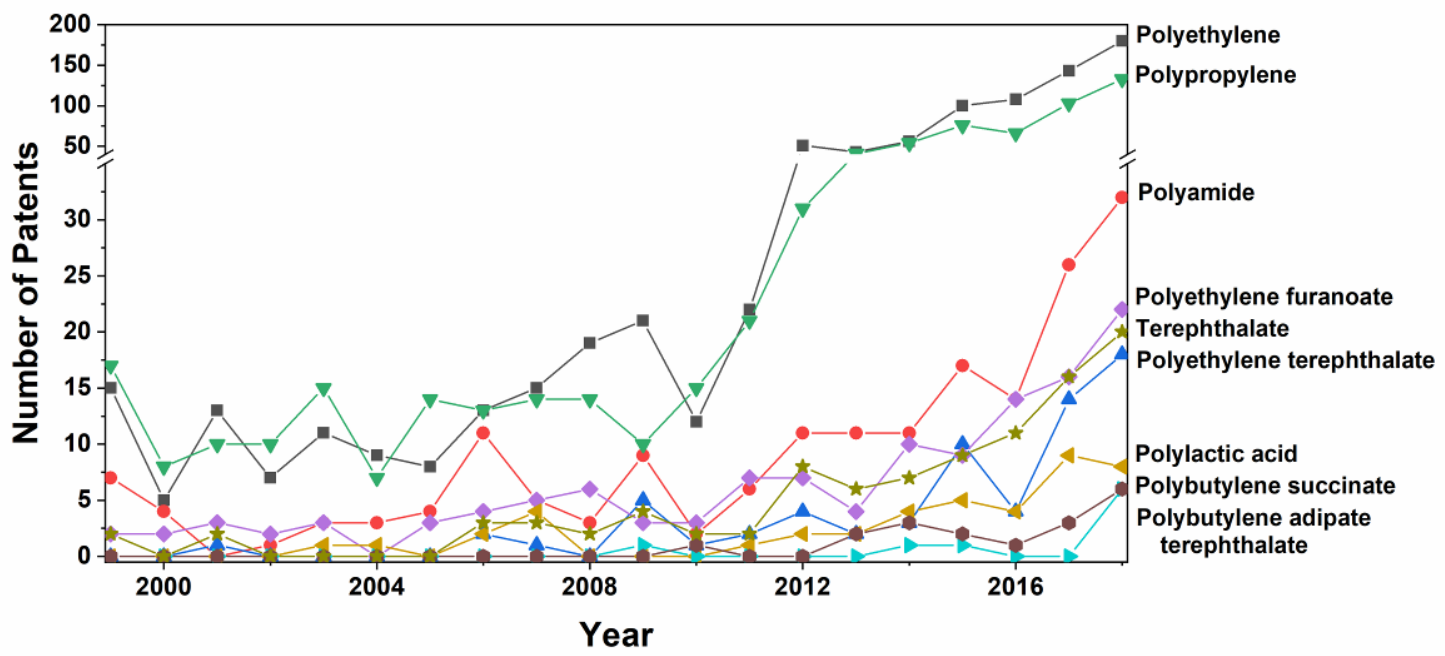

Fig. 6a. Group 3 Google Patent data distribution in the past 20 years

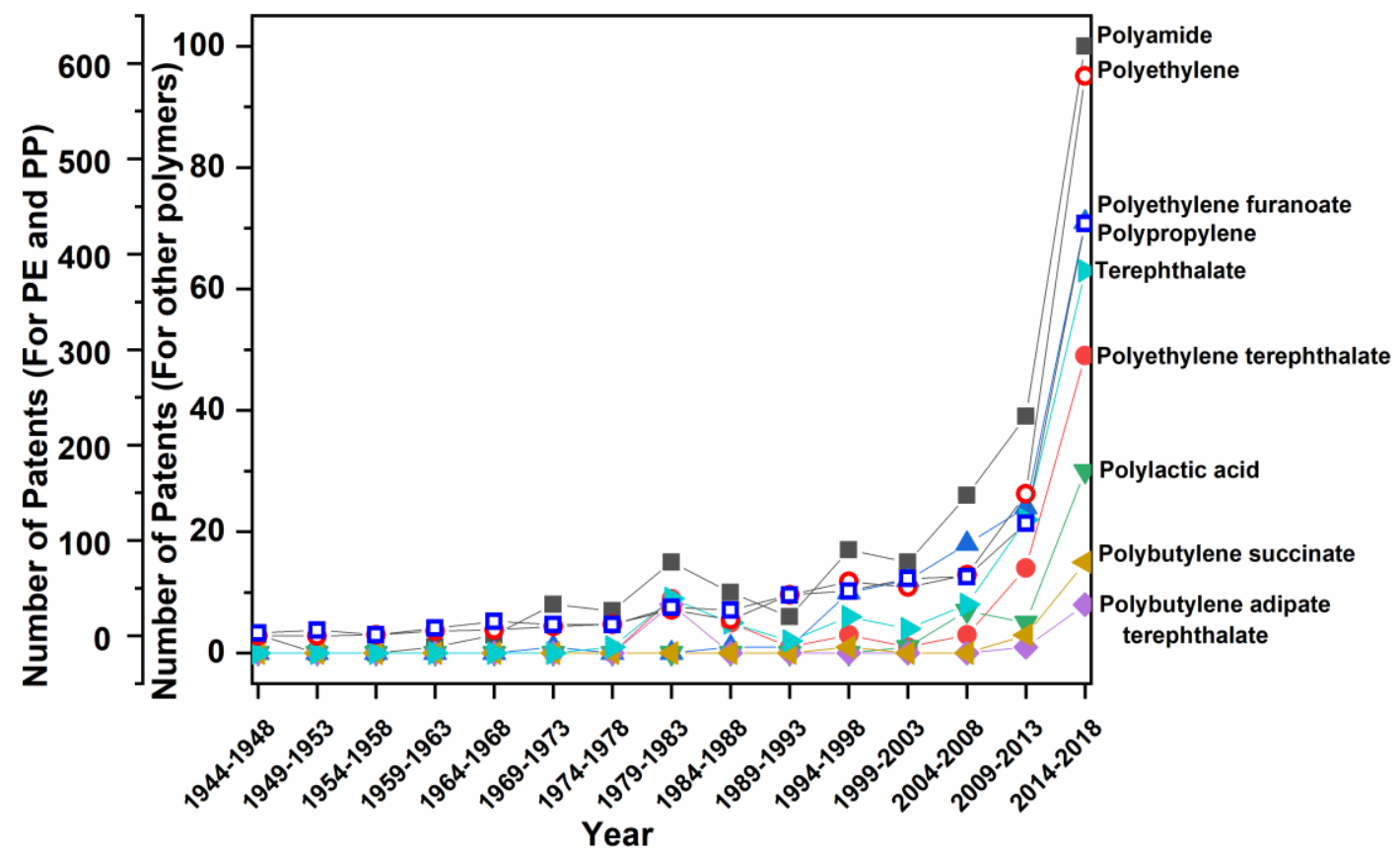

Fig. 6b. Group 3 Google Patent data distribution in the past 90 years 
Recent activity for lignin-based polyethylene, polypropylene, and polyamides was evident in Fig. 6a, especially after 2010. For lignin-based polyethylene furanoate, terephthalate, and terephthalate, a relatively slow incremental increase in patents was observed for recent years (Fig. 6a). Development of the remaining types of lignin-based polymers stabilized and has been of relatively low interest.

Overall, over the next few years, the commercial interest and potential opportunities for lignin-based polymers may focus on lignin-based polyethylene, polypropylene, and polyamide blends.

With regard to the long-term patent activity trends (Fig. 6b), a steadily increasing consistent interest was apparent for all lignin-based polymers. The observed pattern of patents in the $21^{\text {st }}$ century likely indicates a continuing trend and an optimistic future.

\section{CONCLUSIONS}

1. Lignin is among the most promising biomass components currently under development. Due to its natural abundance, global availability, chemical versatility, and its aromaticity, lignin is an attractive renewable substitute for fossil-based chemicals.

2. Notable research and development advances and the increasing focus on sustainable resources are beginning to make lignin recovery for non-fuel purposes attractive (and sometimes mandatory) for pulp producers.

3. The global markets for lignin are expected to grow to a market volume of US\$ 1.12 billion in 2027, with North America in the lead of production and consumption, followed by Europe. The Asia Pacific region is the fastest growing contributor to the global lignin markets. The global production of bioplastics represents less than $1 \%$ of total global plastics production, which currently amounts to approximately 335 million tons. China, with $55 \%$ of the global production, is the largest contributor to the bioplastics market, followed by Europe and North America.

4. The current major resource for most bioplastics is polysaccharides, and the largest proportion of globally produced lignin is used for other applications, such as additives for concrete.

5. The present effort showed strong developmental tendencies aimed at using lignin as a resource for bioplastics and an accompanying increase in the bioplastics market. Lignin will likely be an important resource for the future production of bioplastics.

6. This review showed the existence of a gap between lignin research and development and the actual market.

7. The patent searches and patent trend analyses showed that China, the United States, and Japan are responsible for over half of the patents related to lignin-based polymers. China showed considerably higher patent activity in some novel materials (lignin-based foaming materials and aerogels/hydrogels). In contrast, the United States was found to be focused on more traditional materials (lignin-based thermoplastics, thermosets, and rubbers). 
8. With regard to the temporal distribution findings, an incremental upward trend was apparent for all types of lignin-based polymers. In contrast, lignin-based rubbers showed an extended period of interest from the 1950s to the 1970s.

9. The analyses presented in this review may offer a guideline for interested stakeholders to determine technical development trends for lignin-based polymeric materials.

\section{ACKNOWLEDGEMENTS}

The authors would like to thank their academic advisors, Drs. Frederik Laleicke, Marko Hakovirta, Sunkyu Park, and Yuan Yao for their support.

\section{FUNDING}

This research did not receive any specific grant from funding agencies in the public, commercial, or not-for-profit sectors.

\section{REFERENCES CITED}

Ago, M., Okajima, K., Jakes, J. E., Park, S., and Rojas, O. J. (2012). “Lignin-based electrospun nanofibers reinforced with cellulose nanocrystals," Biomacromolecules 13(3), 918-926. DOI: 10.1021/bm201828g

Ahvazi, B., Wojciechowicz, O., Ton-That, T.-M., and Hawari, J. (2011). "Preparation of lignopolyols from wheat straw soda lignin," Journal of Agricultural and Food Chemistry 59(19), 10505-10516. DOI: 10.1021/jf202452m

Almeida, P. (1996). "Knowledge sourcing by foreign multinationals: Patent citation analysis in the U.S. semiconductor industry," Strategic Management Journal 17(S2), 155-165. DOI: $10.1002 / \mathrm{smj} .4250171113$

Archibugi, D., and Pianta, M. (1992). "Specialization and size of technological activities in industrial countries: The analysis of patent data," Research Policy 21(1), 79-93. DOI: 10.1016/0048-7333(92)90028-3

Argyropoulos, D. S. (2014). "The emerging bio-refinery industry needs to refine lignin prior to use," Journal of Biotechnology and Biomaterials S6, e001. DOI: 10.4172/2155-952X.S6-e001

Argyropoulos, D. S., and Bolker, H. I. (1987a). "The gel degradation theory, Part I; An experimental verification with a model trifunctional network," Macromolecules 20, 2915-2922. DOI: 10.1021/ma00177a046

Argyropoulos, D. S., and Bolker, H. I. (1987b). "The gel degradation theory, Part II; An experimental verification with model networks formed by the random crosslinking of monodisperse primary chains," Die Makromolekulare Chemie 189, 607-618. DOI: 10.1002/macp.1988.021890314

Argyropoulos, D. S., and Bolker, H. I. (1987c). "The gel degradation theory, Part III; An experimental kinetic verification," Journal of Wood Chemistry and Technology 7(4), 499-512. DOI: 10.1080/02773818708085282 
Asada, C., Basnet, S., Otsuka, M., Sasaki, C., and Nakamura, Y. (2015). "Epoxy resin synthesis using low molecular weight lignin separated from various lignocellulosic materials," International Journal of Biological Macromolecules 74, 413-419. DOI: 10.1016/j.ijbiomac.2014.12.039

Barana, D., Ali, S. D., Salanti, A., Orlandi, M., Castellani, L., Hanel, T., and Zoia, L. (2016). "Influence of lignin features on thermal stability and mechanical properties of natural rubber compounds," ACS Sustainable Chemistry \& Engineering 4(10), 52585267. DOI: 10.1021/acssuschemeng.6b00774

Barana, D., Orlandi, M., Zoia, L., Castellani, L., Hanel, T., Bolck, C., and Gosselink, R. (2018). "Lignin based functional additives for natural rubber," ACS Sustainable Chemistry \& Engineering 6(9), 11843-11852. DOI: 10.1021/acssuschemeng.8b02145

Barrett, A. (2018). "The European commission papers: The lignin briefing," Bioplastics News, (https://bioplasticsnews.com/2018/08/10/european-commission-lignin/), Accessed 25 Feb 2019.

Barzegari, M. R., Alemdar, A., Zhang, Y., and Rodrigue, D. (2012). "Mechanical and rheological behavior of highly filled polystyrene with lignin," Polymer Composites 33(3), 353-361. DOI: $10.1002 / \mathrm{pc} .22154$

Belgacem, M. N., and Gandini, A. (2008). Monomers, Polymers and Composites from Renewable Resources, Elsevier, Amsterdam, The Netherlands.

Blažej, A., and Košík, M. (1993). Phytomass: A Raw Material for Chemistry and Biotechnology, Ellis Horwood Ltd., Chichester, England.

Bonini, C., D'Auria, M., Emanuele, L., Ferri, R., Pucciariello, R., and Sabia, A. R. (2005). "Polyurethanes and polyesters from lignin," Journal of Applied Polymer Science 98(3), 1451-1456. DOI: 10.1002/app.22277

Bouajila, J., Dole, P., Joly, C., and Limare, A. (2006). "Some laws of a lignin plasticization," Journal of Applied Polymer Science 102(2), 1445-1451. DOI: 10.1002/app.24299

Bova, T., Tran, C. D., Balakshin, M. Y., Chen, J., Capanema, E. A., and Naskar, A. K. (2016). "An approach towards tailoring interfacial structures and properties of multiphase renewable thermoplasics from lignin-nitrile rubber," Green Chemistry 18(20), 5423-5437. DOI: 10.1039/C6GC01067A

BP Global (2018). "Statistical review of world energy," (https://www.bp.com/en/global/corporate/energy-economics/statistical-review-ofworld-energy.html), Accessed 8 Apr 2019.

Bruijnincx, P., Weckhuysen, B., Gruter, G.-J., and Engelen-Smeets, E. (2016). Lignin Valorisation: The Importance of a Full Value Chain Approach, Utrecht University, Utrecht, The Netherlands.

Canetti, M., and Bertini, F. (2007). "Supermolecular structure and thermal properties of poly(ethylene terephthalate)/lignin composites," Composites Science and Technology 67(15-16), 3151-3157. DOI: 10.1016/j.compscitech.2007.04.013

Canetti, M., and Bertini, F. (2009). "Influence of the lignin on thermal degradation and melting behaviour of poly(ethylene terephthalate) based composites," $e$-Polymers 9(1), Article number 049. DOI: 10.1515/epoly.2009.9.1.596

Cateto, C. A., Barreiro, M. F., Ottati, C., Lopretti, M., Rodrigues, A. E., and Belgacem, M. N. (2014). "Lignin-based rigid polyurethane foams with improved biodegradation," Journal of Cellular Plastics 50(1), 81-95. DOI:

10.1177/0021955X13504774 
Cateto, C. A., Barreiro, M. F., Rodrigues, A. E., and Belgacem, M. N. (2009). "Optimization study of lignin oxypropylation in view of the preparation of polyurethane rigid foams," Industrial \& Engineering Chemistry Research 48(5), 2583-2589. DOI: 10.1021/ie801251r

Chen, K., Qian, Y., Wu, S., Qiu, X., Yang, D., and Lei, L. (2019). "Neutral fabrication of UV-blocking and antioxidation lignin-stabilized high internal phase emulsion encapsulates for high efficient antibacterium of natural curcumin," Food \& Function 10(6), 3543-3555. DOI: 10.1039/C9FO00320G

Cheng, F., and Brewer, C. E. (2017). "Producing jet fuel from biomass lignin: Potential pathways to alkyl-benzenes and cycloalkanes," Renewable and Sustainable Energy Reviews 72, 673-722. DOI: 10.1016/j.rser.2017.01.030

Chuck, C. J., Parker, H. J., Jenkins, R. W., and Donnelly, J. (2013). "Renewable biofuel additives from the ozonolysis of lignin," Bioresource Technology 143, 549-554. DOI: 10.1016/j.biortech.2013.06.048

Chung, H., and Washburn, N. R. (2012). "Improved lignin polyurethane properties with lewis acid treatment," ACS Applied Materials \& Interfaces 4(6), 2840-2846. DOI: 10.1021/am300425x

Chung, Y.-L., Olsson, J. V., Li, R. J., Frank, C. W., Waymouth, R. M., Billington, S. L., and Sattely, E. S. (2013). "A renewable lignin-lactide copolymer and application in biobased composites," ACS Sustainable Chemistry \& Engineering 1(10), 1231-1238. DOI: $10.1021 / \mathrm{sc} 4000835$

Cinelli, P., Anguillesi, I., and Lazzeri, A. (2013). "Green synthesis of flexible polyurethane foams from liquefied lignin,” European Polymer Journal 49(6), 11741184. DOI: 10.1016/j.eurpolymj.2013.04.005

Collins, M. N., Nechifor, M., Tanasă, F., Zănoagă, M., McLoughlin, A., Stróżyk, M. A., Culebras, M., and Teacă, C.-A. (2019). "Valorization of lignin in polymer and composite systems for advanced engineering applications - A review," International Journal of Biological Macromolecules 131, 828-849. DOI:

10.1016/j.ijbiomac.2019.03.069

Cui, C., Sun, R., and Argyropoulos, D. S. (2014). "Fractional precipitation of softwood kraft lignin: Isolation of narrow fractions common to a variety of lignins," ACS Sustainable Chemistry \& Engineering 2(4), 959-968. DOI: 10.1021/sc400545d

da Silva, C. G., Grelier, S., Pichavant, F., Frollini, E., and Castellan, A. (2013). "Adding value to lignins isolated from sugarcane bagasse and Miscanthus," Industrial Crops and Products 42, 87-95. DOI: 10.1016/j.indcrop.2012.04.040

da Silva, E. A. B., Zabkova, M., Araújo, J. D., Cateto, C. A., Barreiro, M. F., Belgacem, M. N., and Rodrigues, A. E. (2009). "An integrated process to produce vanillin and lignin-based polyurethanes from kraft lignin," Chemical Engineering Research and Design 87(9), 1276-1292. DOI: 10.1016/j.cherd.2009.05.008

Datta, J., Parcheta, P., and Surówka, J. (2017). "Softwood-lignin/natural rubber composites containing novel plasticizing agent: Preparation and characterization," Industrial Crops and Products 95, 675-685. DOI: 10.1016/j.indcrop.2016.11.036

de Chirico, A., Armanini, M., Chini, P., Cioccolo, G., Provasoli, F., and Audisio, G. (2003). "Flame retardants for polypropylene based on lignin," Polymer Degradation and Stability 79(1), 139-145. DOI: 10.1016/S0141-3910(02)00266-5

de Oliveira, W., and Glasser, W. G. (1994). "Multiphase materials with lignin. 11. Starlike copolymers with caprolactone," Macromolecules 27(1), 5-11. DOI: 10.1021/ma00079a002 
Doherty, W. O. S., Mousavioun, P., and Fellows, C. M. (2011). "Value-adding to cellulosic ethanol: Lignin polymers," Industrial Crops and Products 33(2), 259-276. DOI: $10.1016 /$ j.indcrop.2010.10.022

Domínguez-Robles, J., Peresin, M. S., Tamminen, T., Rodríguez, A., Larrañeta, E., and Jääskeläinen, A.-S. (2018). "Lignin-based hydrogels with "super-swelling” capacities for dye removal," International Journal of Biological Macromolecules 115, 12491259. DOI: 10.1016/j.ijbiomac.2018.04.044

Du, X., Li, J., and Lindström, M. E. (2014). "Modification of industrial softwood kraft lignin using Mannich reaction with and without phenolation pretreatment," Industrial Crops and Products 52, 729-735. DOI: 10.1016/j.indcrop.2013.11.035

Duong, L. D., Nam, G.-Y., Oh, J.-S., Park, I.-K., Luong, N. D., Yoon, H.-K., Lee, S.-H., Lee, Y., Yun, J.-H., and Lee, C.-G., et al. (2014). "High molecular-weight thermoplastic polymerization of kraft lignin macromers with diisocyanate," BioResources 9(2), 2359-2371. DOI: 10.15376/biores.9.2.2359-2371

Duval, A., and Lawoko, M. (2014). "A review on lignin-based polymeric, micro- and nano-structured materials," Reactive and Functional Polymers 85, 78-96. DOI: 10.1016/j.reactfunctpolym.2014.09.017

Effendi, A., Gerhauser, H., and Bridgwater, A. V. (2008). "Production of renewable phenolic resins by thermochemical conversion of biomass: A review," Renewable and Sustainable Energy Reviews 12(8), 2092-2116. DOI: 10.1016/j.rser.2007.04.008

Engels, H.-W., Pirkl, H.-G., Albers, R., Albach, R. W., Krause, J., Hoffmann, A., Casselmann, H., and Dormish, J. (2013). "Polyurethanes: Versatile materials and sustainable problem solvers for today's challenges," Angewandte Chemie International Edition 52(36), 9422-9441. DOI: 10.1002/anie.201302766

European Bioplastics (2019). "Bioplastic market report 2019," European Bioplastics e.V., (https://www.european-bioplastics.org/market), Accessed 8 Apr 2020.

European Patent Office (2019). "Espacenet: Patent database with over 100 million documents," (https://www.epo.org/searching-forpatents/technical/espacenet.html\#tab-1), Accessed 22 May 2019.

Food and Drug Administration (FDA) (2010). Update on Bisphenol A for Use in Food Contact Applications, US FDA, Silver Spring, MD, USA.

Feldman, D. (2002). "Lignin and its polyblends-A review," in: Chemical Modification, Properties, and Usage of Lignin, T. Q. Hu (ed.), Springer, Boston, MA, USA, pp. 8199.

Figueiredo, P., Lintinen, K., Hirvonen, J. T., Kostiainen, M. A., and Santos, H. A. (2018). "Properties and chemical modifications of lignin: Towards lignin-based nanomaterials for biomedical applications," Progress in Materials Science 93, 233269. DOI: 10.1016/j.pmatsci.2017.12.001

Flint, S., Markle, T., Thompson, S., and Wallace, E. (2012). "Bisphenol A exposure, effects, and policy: A wildlife perspective," Journal of Environmental Management 104, 19-34. DOI: 10.1016/j.jenvman.2012.03.021

Gandini, A., Belgacem, M. N., Guo, Z.-X., and Montanari, S. (2002). "Lignins as macromonomers for polyesters and polyurethanes," in: Chemical Modification, Properties, and Usage of Lignin, T. Q. Hu (ed.), Springer, Boston, MA, USA, pp. 57-80.

Gao, G., Dallmeyer, J. I., and Kadla, J. F. (2012). "Synthesis of lignin nanofibers with ionic-responsive shells: Water-expandable lignin-based nanofibrous mats," Biomacromolecules 13(11), 3602-3610. DOI: 10.1021/bm301039f 
Gardziella, A., Pilato, L. A., and Knop, A. (2000). "Phenolic resins: Chemistry, reactions, mechanism," in: Phenolic Resins, Springer, Berlin, Germany, pp. 24-82.

Gierer, J., and Pettersson, I. (1977). "Studies on the condensation of lignins in alkaline media. Part II. The formation of stilbene and arylcoumaran structures through neighbouring group participation reactions," Canadian Journal of Chemistry 55(4), 593-599. DOI: 10.1139/v77-084

Gigli, M., and Crestini, C. (2020). "Fractionation of industrial lignins: Opportunities and challenges," Green Chem. 22, 4722-4746. DOI: 10.1039/d0gc01606c

Gonçalves, A. R., and Benar, P. (2001). "Hydroxymethylation and oxidation of organosolv lignins and utilization of the products," Bioresource Technology 79(2), 103-111. DOI: 10.1016/S0960-8524(01)00056-6

Google Patents (2019). "Coverage - Google help," (https://support.google.com/faqs/answer/7049585), Accessed 22 May 2019.

Grand View Research (2020). "Lignin market size, growth 2016-2027 | Global industry analysis report," (https://www.grandviewresearch.com/industry-analysis/ligninmarket), Accessed 9 March 2020.

Gregorová, A., Košíková, B., and Moravčík, R. (2006). "Stabilization effect of lignin in natural rubber," Polymer Degradation and Stability 91(2), 229-233. DOI: 10.1016/j.polymdegradstab.2005.05.009

Hatakeyama, H., Hirogaki, A., Matsumua, H., and Hatakeyama, T. (2013). “Glass transition temperature of polyurethane foams derived from lignin by controlled reaction rate," Journal of Thermal Analysis and Calorimetry 114(3), 1075-1082. DOI: $10.1007 / \mathrm{s} 10973-013-3132-1$

Hirose, S., Hatakeyama, T., Izuta, Y., and Hatakeyama, H. (2002). "TG-FTIR studies on lignin-based polycaprolactones," Journal of Thermal Analysis and Calorimetry 70(3), 853-860. DOI: 10.1023/A:1022212421525

Ho, H. C., Goswami, M., Chen, J., Keum, J. K., and Naskar, A. K. (2018). “Amending the structure of renewable carbon from biorefinery waste-streams for energy storage applications," Scientific Reports 8(1), Article number 8355. DOI: 10.1038/s41598018-25880-0

Hofmann, K., and Glasser, W. (1994). "Engineering plastics from lignin, 23. Network formation of lignin-based epoxy resins," Macromolecular Chemistry and Physics 195(1), 65-80. DOI: 10.1002/macp.1994.021950106

Hofmann, K., and Glasser, W. G. (1993). "Engineering plastics from lignin. 22. Cure of lignin-based epoxy resins," The Journal of Adhesion 40(2-4), 229-241. DOI: 10.1080/00218469308031286

Hu, L., Pan, H., Zhou, Y., and Zhang, M. (2011). "Methods to improve lignin's reactivity as a phenol substitute and as replacement for other phenolic compounds: A brief review," BioResources 6(3), 3515-3525.

$\mathrm{Hu}, \mathrm{S}$., Luo, X., and Li, Y. (2014). "Polyols and polyurethanes from the liquefaction of lignocellulosic biomass," ChemSusChem 7(1), 66-72. DOI: 10.1002/cssc.201300760

Hu, T. Q. (2002). Chemical Modification, Properties, and Usage of Lignin, T. Q. Hu (ed.), Springer, Boston, MA, USA.

Huang, C., Ma, J., Zhang, W., Huang, G., and Yong, Q. (2018). "Preparation of lignosulfonates from biorefinery lignins by sulfomethylation and their application as a water reducer for concrete," Polymers 10(8), Article number 841. DOI: $10.3390 /$ polym 10080841 
Huang, J., and Zhang, L. (2002). "Effects of NCO/OH molar ratio on structure and properties of graft-interpenetrating polymer networks from polyurethane and nitrolignin," Polymer 43(8), 2287-2294. DOI: 10.1016/S0032-3861(02)00028-9

Huo, S.-P., Nie, M.-C., Kong, Z.-W., Wu, G.-M., and Chen, J. (2012). “Crosslinking kinetics of the formation of lignin-aminated polyol-based polyurethane foam," Journal of Applied Polymer Science 125(1), 152-157. DOI: 10.1002/app.35401

IBISWorld (2018). "IBISWorld industry report global plastic product \& packaging manufacturing," (https://clients1.ibisworld.com/reports/gl/industry/default.aspx?entid=770), Accessed 8 Apr 2019.

Jiang, X., Liu, J., Du, X., Hu, Z., Chang, H. M., and Jameel, H. (2018). "Phenolation to improve lignin reactivity toward thermosets application," ACS Sustainable Chemistry \& Engineering 6(4), 5504-5512. DOI:10.1021/acssuschemeng.8b00369

Jiao, G.-J., Peng, P., Sun, S.-L., Geng, Z.-C., and She, D. (2019). “Amination of biorefinery technical lignin by Mannich reaction for preparing highly efficient nitrogen fertilizer," International Journal of Biological Macromolecules 127, 544554. DOI: 10.1016/j.ijbiomac.2019.01.076

Jungmeier, G., Van Ree, R., De Jong, E., Stichnothe, H., De Bari, I., Jørgensen, H., Wellisch, M., Bell, G., Spaeth, J., Torr, K., and Kimura, S. (2015). "The "Biorefinery Fact Sheet" and its application to wood based biorefining - Case studies of IEA Bioenergy Task 42 "Biorefining,", in: The $6^{\text {th }}$ Nordic Wood Biorefinery Conference (NWBC) 2015, Helsinki, Finland, pp. 62-68.

Kakroodi, A. R., and Sain, M. (2016). "Lignin-reinforced rubber composites," in: Lignin in Polymer Composites, Elsevier, Waltham, MA, USA, pp. 195-206.

Kim, Y. S., and Kadla, J. F. (2010). "Preparation of a thermoresponsive lignin-based biomaterial through atom transfer radical polymerization," Biomacromolecules 11(4), 981-988. DOI: 10.1021/bm901455p

Konduri, M. K. R., and Fatehi, P. (2015). "Production of water-soluble hardwood kraft lignin via sulfomethylation using formaldehyde and sodium sulfite," ACS Sustainable Chemistry \& Engineering 3(6), 1172-1182. DOI: 10.1021/acssuschemeng.5b00098

Košíková, B., and Gregorová, A. (2005). "Sulfur-free lignin as reinforcing component of styrene-butadiene rubber," Journal of Applied Polymer Science 97(3), 924-929. DOI: 10.1002/app. 21448

Košíková, B., Gregorová, A., Osvald, A., and Krajčovičová, J. (2007). "Role of lignin filler in stabilization of natural rubber-based composites," Journal of Applied Polymer Science 103(2), 1226-1231. DOI: 10.1002/app.24530

Kratzl, K., and Oburger, M. (1980). "Condensation reactions of lignin model compounds with phenol under acid catalysis, 2 [beechwood, spruce wood]," Holzforschung 34(1), 11-16. DOI: 10.1515/hfsg.1980.34.6.191

Kun, D., and Pukánszky, B. (2017). "Polymer/lignin blends: Interactions, properties, applications," European Polymer Journal 93, 618-641. DOI: 10.1016/j.eurpolymj.2017.04.035

Laurichesse, S., and Avérous, L. (2014). "Chemical modification of lignins: Towards biobased polymers," Progress in Polymer Science 39(7), 1266-1290. DOI: 10.1016/j.progpolymsci.2013.11.004

Laurichesse, S., Huillet, C., and Avérous, L. (2014). “Original polyols based on organosolv lignin and fatty acids: New bio-based building blocks for segmented 
polyurethane synthesis," Green Chemistry 16(8), 3958-3970. DOI:

10.1039/C4GC00596A

Li, F., Wang, X., and Sun, R. (2017). “A metal-free and flexible supercapacitor based on redox-active lignosulfonate functionalized graphene hydrogels," Journal of Materials Chemistry A 5(39), 20643-20650. DOI: 10.1039/C7TA03789A

Li, F., Wang, X., Yuan, T., and Sun, R. (2016). "A lignosulfonate-modified graphene hydrogel with ultrahigh adsorption capacity for $\mathrm{Pb}(\mathrm{II})$ removal," Journal of Materials Chemistry A 4(30), 11888-11896. DOI: 10.1039/C6TA03779H

Lin, L., Nakagame, S., Yao, Y., Yoshioka, M., Shiraishi, M. N., and Shiraishi, N. (2001). "Liquefaction mechanism of $\beta-\mathrm{O}-4$ lignin model compound in the presence of phenol under acid catalysis. Part 2. Reaction behaviour and pathways," Holzforschung 55(6), 625-630. DOI: 10.1515/HF.2001.102

Liu, J., Liu, H.-F., Deng, L., Liao, B., and Guo, Q.-X. (2013). “Improving aging resistance and mechanical properties of waterborne polyurethanes modified by lignin amines," Journal of Applied Polymer Science 130(3), 1736-1742. DOI: 10.1002/app.39267

Liu, Y., and Li, K. (2006). "Preparation and characterization of demethylated ligninpolyethylenimine adhesives," The Journal of Adhesion 82(6), 593-605. DOI: $10.1080 / 00218460600766632$

Lora, J. (2008). "Industrial commercial lignins: Sources, properties and applications," in: Monomers, Polymers and Composites from Renewable Resources, M. N. Belgacem, and A. Gandini (eds.), Elsevier, Amsterdam, The Netherlands, pp. 225-241.

Lora, J. H., and Glasser, W. G. (2002). "Recent industrial applications of lignin: A sustainable alternative to non-renewable materials," Journal of Polymers and the Environment 10(1-2), 39-48. DOI: 10.1023/A:1021070006895

L'udmila, H., Michal, J., Andrea, Š., and Aleš, H. (2015). "Lignin, potential products and their market value," Wood Research 60(6), 973-986.

Ma, S., Li, T., Liu, X., and Zhu, J. (2016). "Research progress on bio-based thermosetting resins," Polymer International 65(2), 164-173. DOI: 10.1002/pi.5027

Mansouri, N.-E. E., Yuan, Q., and Huang, F. (2011). "Study of chemical modification of alkaline lignin by the glyoxalation reaction," BioResources 6(4), 4523-4536.

Matsushita, Y., Inomata, T., Takagi, Y., Hasegawa, T., and Fukushima, K. (2011). "Conversion of sulfuric acid lignin generated during bioethanol production from lignocellulosic materials into polyesters with ع-caprolactone," Journal of Wood Science 57(3), 214-218. DOI: 10.1007/s10086-010-1158-6

Matsushita, Y., and Yasuda, S. (2003). "Reactivity of a condensed-type lignin model compound in the Mannich reaction and preparation of cationic surfactant from sulfuric acid lignin," Journal of Wood Science 49(2), 166-171. DOI: $10.1007 / \mathrm{s} 100860300026$

Maurseth, P. B., and Verspagen, B. (2002). "Knowledge spillovers in Europe: A patent citations analysis," The Scandinavian Journal of Economics 104(4), 531-545. DOI: 10.1111/1467-9442.00300

Mendis, G. P., Hua, I., Youngblood, J. P., and Howarter, J. A. (2015). "Enhanced dispersion of lignin in epoxy composites through hydration and Mannich functionalization," Journal of Applied Polymer Science 132, Article ID 41263. DOI: 10.1002/app.41263 
Meng, Y., Lu, J., Cheng, Y., Li, Q., and Wang, H. (2019). "Lignin-based hydrogels: A review of preparation, properties, and application," International Journal of Biological Macromolecules 135, 1006-1019. DOI: 10.1016/j.ijbiomac.2019.05.198

Mogee, M. E. (1991). "Using patent data for technology analysis and planning," Research-Technology Management 34(4), 43-49. DOI: 10.1080/08956308.1991.11670755

Mu, Y. B., Wang, C.-P., Zhao, L.-W., and Chu, F.-X. (2009). "Study on composite adhesive of hydroxymethylated lignosulfonate/phenol-formaldehyde resin with low free formaldehyde," Chemistry and Industry of Forest Products 29(3), 38-42.

Nadji, H., Bruzzèse, C., Belgacem, M. N., Benaboura, A., and Gandini, A. (2005). "Oxypropylation of lignins and preparation of rigid polyurethane foams from the ensuing polyols," Macromolecular Materials and Engineering 290(10), 1009-1016. DOI: $10.1002 /$ mame.200500200

Naegele, H., Pfitzer, J., Ziegler, L., Inone-Kauffmann, E. R., and Eisenreich, N. (2016). "Applications of lignin materials and their composites (lignin applications in various industrial sectors, future trends of lignin and their composites)," in: Lignin in Polymer Composites, William Andrew Publishing, New York, NY, USA, pp. 233-244.

Nahmany, M., and Melman, A. (2004). "Chemoselectivity in reactions of esterification," Organic \& Biomolecular Chemistry 2(11), 1563-1572. DOI: 10.1039/B403161J

Nimz, H. (1969). "Condensation reactions of lignin: Reaction of lignin model compounds with resorcinol and hydrochloric acid," Holzforschung 23(3), 84-88. DOI: 10.1515/hfsg.1969.23.3.84

Ogunkoya, D., Li, S., Rojas, O. J., and Fang, T. (2015). "Performance, combustion, and emissions in a diesel engine operated with fuel-in-water emulsions based on lignin," Applied Energy 154, 851-861. DOI: 10.1016/j.apenergy.2015.05.036

Olivares, M., Guzmán, J. A., Natho, A., and Saavedra, A. (1988). "Kraft lignin utilization in adhesives," Wood Science and Technology 22(2), 157-165. DOI: 10.1007/BF00355851

Oltra, V., and Saint-Jean, M. (2009). "Variety of technological trajectories in low emission vehicles (LEVs): A patent data analysis," Journal of Cleaner Production 17(2), 201-213. DOI: 10.1016/j.jclepro.2008.04.023

Pan, H., Sun, G., and Zhao, T. (2013). "Synthesis and characterization of aminated lignin," International Journal of Biological Macromolecules 59, 221-226. DOI: 10.1016/j.ijbiomac.2013.04.049

Passauer, L. (2012). "Highly swellable lignin hydrogels: Novel materials with interesting properties," in: Functional Materials from Renewable Sources, F. Liebner, and T. Rosenau (eds.), American Chemical Society, Washington D.C., USA, pp. 211-228.

Passoni, V., Scarica, C., Levi, M., Turri, S., and Griffini, G. (2016). "Fractionation of industrial softwood kraft lignin: Solvent selection as a tool for tailored material properties," ACS Sustainable Chemistry \& Engineering 4(4), 2232-2242. DOI: 10.1021/acssuschemeng.5b01722

Peng, Z., Zou, Y., Xu, S., Zhong, W., and Yang, W. (2018). "High-performance biomassbased flexible solid-state supercapacitor constructed of pressure-sensitive ligninbased and cellulose hydrogels," ACS Applied Materials \& Interfaces 10(26), 2219022200. DOI: 10.1021/acsami.8b05171

Perlack, R. D., Wright, L. L., Turhollow, A. F., Graham, R. L., Stokes, B. J., and Erbach, D. C. (2005). Biomass as Feedstock for a Bioenergy and Bioproducts Industry: The 
Technical Feasibility of a Billion-ton Annual Supply, Oak Ridge National Laboratory, Oak Ridge, TN, USA.

Pohjanlehto, H., Setälä, H. M., Kiely, D. E., and McDonald, A. G. (2014). “Ligninxylaric acid-polyurethane-based polymer network systems: Preparation and characterization," Journal of Applied Polymer Science 131(1), Article ID 39714. DOI: 10.1002/app.39714

Pouteau, C., Baumberger, S., Cathala, B., and Dole, P. (2004). "Lignin-polymer blends: Evaluation of compatibility by image analysis," Comptes Rendus Biologies 327(910), 935-943. DOI: 10.1016/j.crvi.2004.08.008

Pouteau, C., Dole, P., Cathala, B., Averous, L., and Boquillon, N. (2003). "Antioxidant properties of lignin in polypropylene," Polymer Degradation and Stability 81(1), 918. DOI: 10.1016/S0141-3910(03)00057-0

Raquez, J.-M., Deléglise, M., Lacrampe, M.-F., and Krawczak, P. (2010). "Thermosetting (bio)materials derived from renewable resources: A critical review," Progress in Polymer Science 35(4), 487-509. DOI:

10.1016/j.progpolymsci.2010.01.001

Rossilo-Calle, F., de Groot, P., Hemstock, S. L., and Woods, J. (2007). The Biomass Assessment Handbook, Earthscan, London, England.

Sadeghifar, H., and Argyropoulos, D. S. (2015). "Correlations of the antioxidant properties of softwood kraft lignin fractions with the thermal stability of its blends with polyethylene," ACS Sustainable Chemistry \& Engineering 3(2), 349-356. DOI: $10.1021 / \mathrm{sc} 500756 \mathrm{n}$

Sadeghifar, H., and Argyropoulos, D. S. (2016). "Macroscopic behavior of kraft lignin fractions: Melt stability considerations for lignin-polyethylene blends," ACS Sustainable Chemistry \& Engineering 4(10), 5160-5166. DOI: 10.1021/acssuschemeng.6b00636

Sadeghifar, H., Cui, C., and Argyropoulos, D. S. (2012). "Toward thermoplastic lignin polymers. Part 1. Selective masking of phenolic hydroxyl groups in kraft lignins via methylation and oxypropylation chemistries," Industrial \& Engineering Chemistry Research 51(51), 16713-16720. DOI: 10.1021/ie301848j

Schutyser, W., Renders, T., Van den Bosch, S., Koelewijn, S.-F., Beckham, G. T., and Sels, B. F. (2018). "Chemicals from lignin: An interplay of lignocellulose fractionation, depolymerisation, and upgrading," Chemical Society Reviews 47(3), 852-908. DOI: 10.1039/C7CS00566K

Sen, S., Patil, S., and Argyropoulos, D. S. (2015). "Thermal properties of lignin in copolymers, blends, and composites: A review," Green Chemistry 17(11), 4862-4887. DOI: $10.1039 / \mathrm{C} 5 \mathrm{GC} 01066 \mathrm{G}$

Setua, D. K., Shukla, M. K., Nigam, V., Singh, H., and Mathur, G. N. (2000). "Lignin reinforced rubber composites," Polymer Composites 21(6), 988-995. DOI: $10.1002 / \mathrm{pc} .10252$

Su, L., Xing, Z., Wang, D., Xu, G., Ren, S., and Fang, G. (2013). “Mechanical properties research and structural characterization of alkali lignin / poly(vinyl alcohol) reaction films," BioResources 8(3), 3532-3543. DOI: 10.15376/biores.8.3.3532-3543

Sun, Z., Fridrich, B., de Santi, A., Elangovan, S., and Barta, K. (2018). "Bright side of lignin depolymerization: Toward new platform chemicals," Chemical Reviews 118(2), 614-678. DOI: 10.1021/acs.chemrev.7b00588 
Tan, T. T. M. (1996). "Cardanol-lignin-based polyurethanes," Polymer International 41(1), 13-16. DOI: 10.1002/(SICI)1097-0126(199609)41:1<13::AIDPI557>3.0.CO;2-8

Thakur, S., Govender, P. P., Mamo, M. A., Tamulevicius, S., Mishra, Y. K., and Thakur, V. K. (2017). "Progress in lignin hydrogels and nanocomposites for water purification: Future perspectives," Vacuum 146, 342-355. DOI: 10.1016/j.vacuum.2017.08.011

Thakur, V. K., Thakur, M. K., Raghavan, P., and Kessler, M. R. (2014). "Progress in green polymer composites from lignin for multifunctional applications: A review," ACS Sustainable Chemistry \& Engineering 2(5), 1072-1092. DOI: $10.1021 / \mathrm{sc} 500087 \mathrm{z}$

Thring, R. W., Vanderlaan, M. N., and Griffin, S. L. (1997). "Polyurethanes from Alcell@ lignin," Biomass and Bioenergy 13(3), 125-132. DOI: 10.1016/S09619534(97)00030-5

Tran, C. D., Chen, J., Keum, J. K., and Naskar, A. K. (2016). "A new class of renewable thermoplastics with extraordinary performance from nanostructured ligninelastomers," Advanced Functional Materials 26(16), 2677-2685. DOI: 10.1002/adfm.201504990

Trappey, C. V., Wu, H.-Y., Taghaboni-Dutta, F., and Trappey, A. J. C. (2011). “Using patent data for technology forecasting: China RFID patent analysis," Advanced Engineering Informatics 25(1), 53-64. DOI: 10.1016/j.aei.2010.05.007

Tribot, A., Amer, G., Abdou Alio, M., de Baynast, H., Delattre, C., Pons, A., Mathias, J.D., Callois, J.-M., Vial, C., and Michaud, P., et al. (2019). "Wood-lignin: Supply, extraction processes and use as bio-based material," European Polymer Journal 112, 228-240. DOI: 10.1016/j.eurpolymj.2019.01.007

Tuck, C. O., Pérez, E., Horváth, I. T., Sheldon, R. A., and Poliakoff, M. (2012). "Valorization of biomass: Deriving more value from waste," Science 337(6095), 695699. DOI: $10.1126 /$ science. 1218930

Upton, B. M., and Kasko, A. M. (2016). "Strategies for the conversion of lignin to highvalue polymeric materials: Review and perspective," Chemical Reviews 116(4), 2275-2306. DOI: 10.1021/acs.chemrev.5b00345

Vanderlaan, M. N., and Thring, R. W. (1998). "Polyurethanes from Alcell ${ }^{\circ}$ lignin fractions obtained by sequential solvent extraction," Biomass and Bioenergy 14(5-6), 525-531. DOI: 10.1016/S0961-9534(97)10058-7

Wang, C., Kelley, S. S., and Venditti, R. A. (2016). "Lignin-based thermoplastic materials," ChemSusChem 9(8), 770-783. DOI: 10.1002/cssc.201501531

Wang, H., Liu, W., Huang, J., Yang, D., and Qiu, X. (2018). "Bioinspired engineering towards tailoring advanced lignin/rubber elastomers," Polymers 10(9), Article number 1033. DOI: 10.3390/polym10091033

Wang, H., Ruan, H., Pei, H., Wang, H., Chen, X., Tucker, M. P., Cort, J. R., and Yang, B. (2015). "Biomass-derived lignin to jet fuel range hydrocarbons via aqueous phase hydrodeoxygenation," Green Chemistry 17(12), 5131-5135. DOI: 10.1039/C5GC01534K

Wang, J., Manley, R. S. J., and Feldman, D. (1992). "Synthetic polymer-lignin copolymers and blends," Progress in Polymer Science 17(4), 611-646. DOI: 10.1016/0079-6700(92)90003-H

Wang, J., Yao, K., Korich, A. L., Li, S., Ma, S., Ploehn, H. J., Iovine, P. M., Wang, C., Chu, F., and Tang, C. (2011). "Combining renewable gum rosin and lignin: Towards 
hydrophobic polymer composites by controlled polymerization," Journal of Polymer Science Part A: Polymer Chemistry 49(17), 3728-3738. DOI: 10.1002/pola.24809

Witter, D. (2015). IBIS World Industry Report 32521: Plastic \& Resin Manufacturing in the US, IBIS World, Melbourne, Australia.

Witzler, M., Alzagameem, A., Bergs, M., Khaldi-Hansen, B. E., Klein, S. E., Hielscher, D., Kamm, B., Kreyenschmidt, J., Tobiasch, E., and Schulze, M. (2018). "Ligninderived biomaterials for drug release and tissue engineering," Molecules 23(8), Article number 1885. DOI: 10.3390/molecules23081885

Xu, W., Wang, X., Sandler, N., Willför, S., and Xu, C. (2018). “Three-dimensional printing of wood-derived biopolymers: A review focused on biomedical applications," ACS Sustainable Chemistry \& Engineering 6(5), 5663-5680. DOI: 10.1021/acssuschemeng.7b03924

Yu, P., He, H., Jia, Y., Tian, S., Chen, J., Jia, D., and Luo, Y. (2016). “A comprehensive study on lignin as a green alternative of silica in natural rubber composites," Polymer Testing 54, 176-185. DOI: 10.1016/j.polymertesting.2016.07.014

Zhang, Q., Zhang, G., Xu, J., Gao, C., and Wu, Y. (2015). "Recent advances on ligninderived polyurethane polymers," Reviews on Advanced Materials Science 40(2), 146154.

Zhang, W., Ma, Y., Wang, C., Li, S., Zhang, M., and Chu, F. (2013). "Preparation and properties of lignin-phenol-formaldehyde resins based on different biorefinery residues of agricultural biomass," Industrial Crops and Products 43, 326-333. DOI: 10.1016/j.indcrop.2012.07.037

Zhu, H., Peng, Z., Chen, Y., Li, G., Wang, L., Tang, Y., Pang, R., Khan, Z. U. H., and Wan, P. (2014). "Preparation and characterization of flame retardant polyurethane foams containing phosphorus-nitrogen-functionalized lignin," RSC Advances 4(98), 55271-55279. DOI: 10.1039/C4RA08429B

Article submitted: August 13, 2020; Peer review completed: September 13, 2020; Revised version received and accepted: November 18, 2020; Published: November 23, 2020.

DOI: 10.15376/biores.16.1.Kropat 